\title{
Multi-objective non-weighted optimization to explore new efficient design of electrical microgrids
}

\author{
Nathanael Dougier ${ }^{1}$, Pierre Garambois ${ }^{* 1}$, Julien Gomand ${ }^{1}$, Lionel Roucoules ${ }^{1}$ \\ ${ }^{1}$ Arts et Metiers Institute of Technology, LISPEN, HESAM Université, F-13617 Aix-en-Provence, FRANCE \\ *Corresponding author. Tel.: +33-442938222. E-mail address: pierre.garambois@ensam.eu
}

\begin{abstract}
Centralized electrical networks induce a dependency of local territories for their power supply. However, thanks to microgrids, territories can increase their decision-making autonomy to design a network that matches their values. Technological and management choices are critical to minimize microgrids negative impacts on their environment. Influence of the latter on the design space is rarely discussed whereas extending the design space would help to find innovative microgrids. The purpose of this paper is to find several microgrids with various performances and parameters that are compromises between economic, technical and environmental objectives. The solutions' variety therefore extends the decision-makers' design space. A tool has been developed to answer this goal. Design parameters are both technological and management parameters. A physical modelling is implemented in a sequential simulation of the microgrid operation. The performance of the simulation allows to use genetic algorithms to perform multi-objective non-weighted optimizations. Two twoobjective optimizations are performed. Results show how the solutions' diversity in terms of performances and parameters helps the user choosing innovative microgrids. Especially, it underlines the potential of this approach to find microgrids with close performances but different parameters.
\end{abstract}

Keywords: decision-support tool, microgrid modelling, multi-objective optimization, energy system simulation, genetic algorithm

\section{Introduction}

1.1. Context

Electricity plays an increasing role in the energy supply. The economic, technical and environmental impacts of the electricity supply depend on the installed technologies and their management. In the past century, cost reduction has prevailed over environmental concerns to design centralized electrical networks. Many local territories want now to relocate their electricity production in order to reduce their environmental impact. Local production is possible thanks to distributed energy resources, i.e. small generation units connected to the distribution network [1], and storage technologies balancing production intermittency [2]. These technologies can be gathered in a microgrid in order to improve the resilience to natural disasters or cascading power failure [3]. There is not a unique definition of a microgrid [4], [5]. In this article, we define it as a set of distributed energy production, storage and consumption devices with their management strategies. From the main network point of view, a microgrid acts as a single controllable entity [6]. Microgrids have been studied both numerically [7]-[10] and experimentally [11], [12]. Complementarity among technologies is the key to their development. 


\subsection{Discussion of the state of the art}

Design of a microgrid has a major influence on its performances. It can improve the decisionmaking autonomy by considering microgrids with unconventional characteristics in order to shake the designer's habits. In this paper, embodiment design [13] of a microgrid consists in choosing the nature and size of the installed production and storage technologies and their management strategies. The decision-maker's objectives and the design space's limits influence the final microgrid design. Some commercial software [14], [15] or studies [16], [17] assess the performances of one specific microgrid but the risk is to study only combinations of technologies designers know. Among the optimization studies that search for optimal solutions among the design space, a majority of scientific literature and commercial software focuses on single-objective optimization. They use a single economic objective [18], [19] or an aggregated function [20]-[23]. Therefore, they do not consider all impacts and they reduce the decisionmaking autonomy by suggesting a unique solution. Non-weighted multi-objective studies often combine two or three economic, technical or environmental objectives. Some of them find several solutions [24]-[27] but fewer analyze the design space based on the solutions' parameters [28], [29]. Such analysis of the design space is important to propose innovative microgrids. Moreover, in these latter studies, technological parameters are used as optimization variables but management parameters are fixed. Due to the impact of management on the energy flows and thus on the performances, different strategies could highlight microgrids that underperform with the usual strategy. The influence of these strategies on the design space is poorly documented today.

\subsection{Objectives and contributions}

The purpose of this work is to increase the decision-making autonomy of local territories in the design of their microgrid. The design space extension is underlined by the use of a nonweighted multi-objective optimization (NSGA-II algorithm) and by the consideration of both technological and management parameters as design parameters. Economic, technical and environmental performances are considered. This article shows how finding various compromises helps choosing appropriate and unconventional microgrids. A decision-support tool has been created on MATLAB software. Its goals are (1) to find various microgrids with different performances and parameters and (2) to find several alternative microgrids having the same performances. To reach these goals, the tool needs to complete several features.

- Modelling of all technologies based on physical phenomena.

- Simulation of a microgrid operation.

- Evaluation of economic, technical and environmental performances of a microgrid.

- Multi-objective optimization of microgrids in order to find several solutions.

The tool should also be modular in order to accept new technologies, management strategies and performance indicators. This way, it will be resilient to changes in the design context: evolution of technologies or industrial context, new society's concerns etc.

Figure 1 summarizes the features of the developed tool. Inputs of the study are the meteorological data and the electrical consumption (in green). Each technology is modelled (orange boxes). Blue lines represent the simulation of the microgrid operation. Evaluation process to assess microgrid performances is gathered in the blue box. Finally, yellow boxes correspond to the optimization steps. At the end of the optimization, the tool displays the Pareto-optimal solutions. 
The main contributions of this work are:

- Microgrids modelling based on physical phenomena and considering both design and management parameters ;

- Development of a modular decision-support tool finding various microgrids, compromises between economic, technical and environmental objectives ;

- Non-weighted multi-objective optimization that highlights interesting solutions like microgrids with close performances but different parameters.

The rest of the paper is structured as follows. Section 2 presents the state of the art. Modelling and simulation methods are described in Section 3. Section 4 deals with the optimization method while the case study parameters are presented in Section 5. Section 6 displays the case study results and Section 7 analyzes them. Finally, Section 8 contains a conclusion and perspectives for a future work.

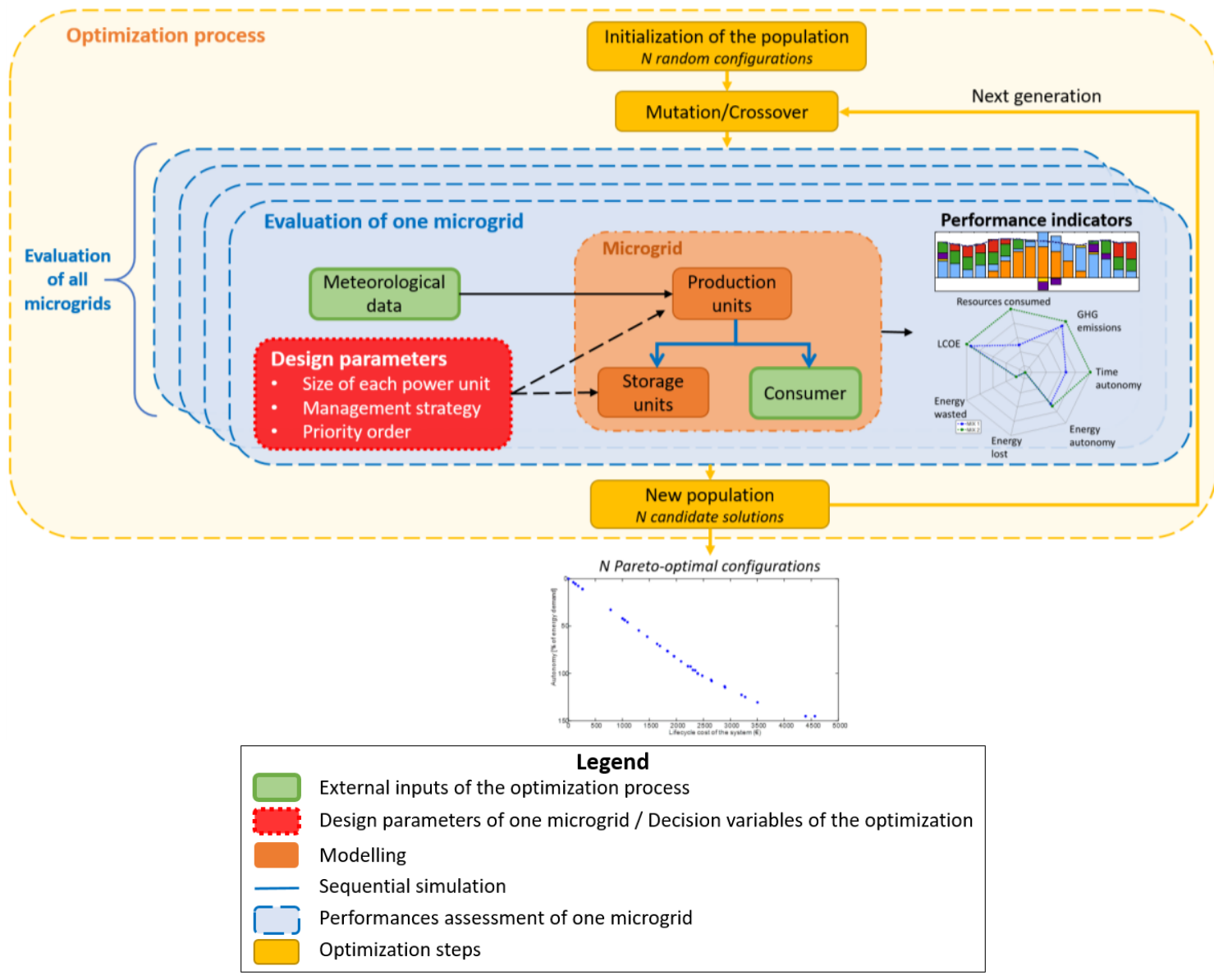

Figure 1: Main features of the tool, which are the main steps of the presented work

\section{State of the art discussion}

2.1. Physical modelling and simulation

The choice of a local microgrid implies understanding the behavior of each technology and of the microgrid in general. Indeed, performance indicators of a microgrid rely on its design parameters but also on its operation. Different approaches exist to model and simulate the operation of microgrids [30]. 
On the one hand, prospective studies consider large areas and assess technological choices over a long-term period [31]-[33]. They take into account main energy flows, economic impacts and technological breakthroughs. However, they model the energy system using aggregated parameters, sometimes far from the technological parameters, such as capital, labor or climatic impacts [34], [35]. They use daily or even yearly time steps to simulate the long-term operation in a reasonable time. They lack accuracy for small-scale studies, simplify the physical phenomena involved and reduce the number of design variables available.

On the other hand, detailed studies assess the performances of specific microgrids [16], [17]. Their microgrid models require detailed information about the studied microgrid, in particular its architecture. They simulate dynamic behavior of the microgrid with a short time step. Each model is made for a specific case study and requires substantial work to be adapted to another microgrid. Rare studies use local technological parameters as optimization variables [36].

Trade-offs, such as HOMER software, model technologies based on hourly physical phenomena, simulate the operation with an hourly time step and are replicable to several case study [37]. However, HOMER is a commercial software so one cannot implement new models. Furthermore, its optimization process finds a unique solution whereas we want various compromises.

The present work does not focus on the dynamic behavior of electrical systems nor on their long-term evolution. It tries to capture the interactions between physical phenomena and microgrids performances. Modelling based on physical phenomena helps to understand how technological features achieve functional ones and thus to find unconventional microgrids [38]. The level of details of a model and the number of design parameters that need to be taken into account can vary according to the scale of the studied system but also the computation-time (CPU-time) needed. The present study takes into account hourly physical phenomena affecting local conversion and storage of energy.

\subsection{Performances indicators}

Regarding the complexity of energy topics, this study considers economic, technical and environmental impacts of microgrids. Economic indicators evaluate the costs of a microgrid. They can focus on the lifecycle costs, the investment costs, the operation and maintenance (O\&M) costs, the payback period or the internal rate of return [39]. Each indicator has its advantages and limitations and can be discussed, as pointed by [40]. For example, minimizing the levelized cost of energy (LCOE, described in Section 3.5.1) leads to a low level of energy not supplied, whereas some other economic indicators lead to the contrary [40]. Technical indicators define the impact of the microgrid on the power supply. Various indicators can be found in the literature: energy not supplied [41], loss of load expectation (LOLE) [41], loss of load probability (LOLP) [42], wasted renewable energy [20] or autonomy level [43]. As this study focuses on microgrids, the autonomy level (LA) from the main power grid appears to be a good indicator of the microgrid ability to replace the main grid. Eventually, environmental indicators assess the impacts on the environment such as soil contamination, loss of biodiversity or greenhouse gases emissions [44], [45]. Many indicators can represent the environmental impact but global warming is undoubtedly a major concern for our societies.

The developed tool includes several indicators to avoid the use of many different software. Economic and environmental indicators are often antagonists [46]. Therefore, only compromises between the different objectives can be found. The paper defines one indicator of each category: the LCOE, the energy autonomy to the main grid and the greenhouse gases emissions (GES). Previous works have compared indicators from different categories [47]. The 
present work focuses on the tool and its abilities, but does not intend to study in detail all indicators. For a specific technology, the relation between economic, technical and environmental indicators can be guessed but for a whole microgrid, composed of several technologies, it is not trivial and may depend on the local context.

\subsection{Multi-objective optimization}

Modelling and simulation of one microgrid allows assessing its performances. Once the performance indicators defined, an optimization process is used to find the best microgrids for a territory. Many microgrid optimizations have been used in the literature [18], [19], [21]-[26]. In the majority of the microgrid optimizations, single-objective (SO) optimization is used with an economic objective [18], [19]. Aggregated functions are also used to compute several indicators in a single function, such as overall cost and greenhouse gases emissions [20]-[23], [48]. However, weighting objectives a priori is subjective and restrains the solution space to one unique solution. Due to the objectives' potential antagonism, it is not adapted to our purpose. A multi-objective (MO) optimization without aggregation is more adapted to find several compromises and to extend the decision-maker's possibilities. Some MO optimizations without prior weighting are also performed [24]-[26], [49].

In the case of microgrid models with a sequential simulation, objective functions do not have an explicit form, which makes it impossible to use a classic Lagrangian optimization method. When it comes to non-explicit formulation problems, metaheuristic methods are an efficient way to perform optimization in a wide design space. Therefore, the optimization is based on a metaheuristic algorithm that allows studying non-explicit and non-weighted objective-functions in order to explore the entire design space.

Many metaheuristics methods are used in the literature in order to perform MO optimization: Particle Swarm Optimization [27], [50] and MO Evolutionary Algorithms (MOEA) methods [49], among others. In this field, evolutionary methods present two main advantages: they can deal with 0 -order objective functions and they explore the total design space. Many evolutionary methods are available like Strength Pareto Evolutionary Algorithms (SPEA [51] and SPEA-II [52]), Non-dominated Sorting Genetic Algorithms (NSGA and NSGA-II [53]), Pareto Archived Evolution Strategy (PAES [54]) or Adaptive Pareto Algorithm (APA [55]). All these methods allow finding Pareto-optimal solutions between the various objectives, i.e. solutions that dominate the others on at least one objective, which is the objective of this paper. Their main disadvantage is their CPU-time due to the repetition of the criteria's evaluation for each individual. However, the model of the microgrid described above is efficient enough, in terms of CPU-time, to balance the number of computations of the metaheuristic method. Among MOEA algorithms, NSGA-II method shows good performances compared to others, it is freely available, easy to handle and modify and already mastered in the laboratory.

Even though non-weighted MO optimization finds several Pareto-optimal solutions, additional post-processing of the tested microgrids can increase the solution space by highlighting nearoptimal solutions. These solutions are very close to the Pareto-front in terms of performances and may have different characteristics. For example, authors in [56] use a modified PSO algorithm with additional post-processing to provide multiple design options to microgrid developers. This design space expansion is very interesting and will be investigated in future works. 


\section{Modelling, simulation and evaluation of one microgrid}

In the perspective of a daily work, the tool must perform the optimization process in a few hours. Therefore, microgrid model has to be detailed to consider hourly physical phenomena and fast to assess numerous microgrids in a few hours during the optimization process.

\subsection{Description of a microgrid}

The local context imposes external inputs of the microgrid model such as the electric consumption and meteorological data. It also imposes some parameters of the microgrid such as available technologies and their technological characteristics.

In this study, the design parameters of a microgrid are technological and management parameters. Technological ones are the size of each generation or storage unit (number of wind turbines, surface of photovoltaic panels, battery's installed capacity...). Management parameters are the priority order, in which technologies are solicited to deliver electricity, and local management strategy of each power unit. Additional technological parameters are used in the models but they are fixed for all the study and do not define a microgrid. Design parameters are also the decision variables of the optimization process.

\subsection{Local device models}

The production and storage technologies described in this article are wind turbines, photovoltaic panels, gas and biomass power plants, battery and pumped-hydroelectricity energy storage (PHES). However, others have been modelled (dam, run-of-river dam, fuel cell and other power plants like coal or nuclear). All models are based on generic modelling from the literature. Generating units are divided into two categories: controllable ones for which the output power can be managed and uncontrollable ones relying on intermittent resources. The modularity of the tool allows to add new models or new technologies.

For all models, the chosen convention fixes the power as positive when a unit produces/discharges energy and negative when it consumes energy. Energy exchanges between the different installations are assumed to be with constant power over a time step.

\subsubsection{Uncontrollable production technologies}

- Wind turbine

The model used to compute the power produced by a wind turbine is based on the power curve of a specific turbine, the Vestas V90/2MW [57] (see Figure 2).

$P_{W T}=P(v)$

With $v$ the wind speed (in $\mathrm{m} / \mathrm{s}$ ). 


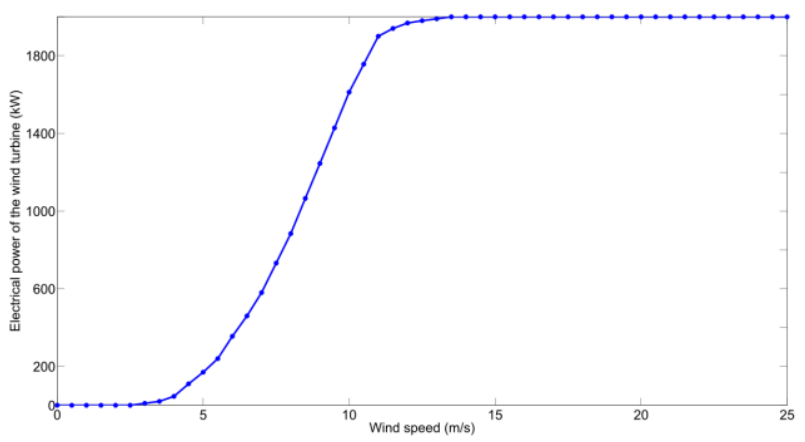

Figure 2: Power curve of the wind turbine Vestas V90/2MW in function of the wind speed

- Photovoltaic panel

Model for the photovoltaic (PV) panel is the following, commonly used in the literature [58]:

$P_{P V}=\operatorname{Irr} . S . \eta$

With $\operatorname{Irr}$ the solar irradiation (in $\mathrm{W} / \mathrm{m}^{2}$ ), $S$ the surface of the installation and $\eta$ the efficiency of the panel.

\subsubsection{Controllable production technologies}

Controllable technologies modelled here are gas and biomass power plants. Controllable units are characterized by their installed power $P_{c t r l, n o m}$ and the output power increase ramp limit $\alpha_{c t r l}$. Therefore, during the sequential simulation, we define the generated power $P_{c t r l}$ according to the needs and the production capacity (see Equation 3 ).

$P_{c t r l}(t+1)=\min \left(P_{c t r l, n o m} ; P_{c t r l}(t)+\alpha_{c t r l} . P_{c t r l}(t) ; P_{\text {needed }}(t)\right)$

with $P_{c t r l}$ the effective electrical output power, $P_{c t r l, n o m}$ the nominal power of the controllable power plant, $\alpha_{c t r l}$ the coefficient representing the power ramp-up limit and $P_{\text {needed }}$ the required power to balance consumption and optionally to store energy according to the chosen local management strategy (see Section 3.3.3), at time step $t$.

\subsubsection{Storage technologies}

For storage systems, a common linear model has been used with different parameters according to the technology [59]. All technologies are defined by their capacity $\left(E_{\text {sto }}\right.$, in Wh), their (dis)charging rate $\left(\mathrm{C}\right.$-rate, in $\left.\mathrm{h}^{-1}\right)$, their loss coefficient during charge/discharge $\left(\alpha_{\text {stor }}\right)$, their auto-discharge coefficient $\left(\alpha_{\text {auto }}\right)$ and auto-discharge reference period $\left(T_{\text {ref }}\right)$. To assess the evolution of their charge, we use a common dimensionless criterion, the State of Energy (SoE), defined by Equation 4 as the installed capacity percentage. A SoE of $100 \%$ represents a fully charged state and $0 \%$ a complete discharge. However, each storage system has a minimum SoE, representing the deep discharge, under which storage systems like batteries can be damaged [59].

$$
\operatorname{SoE}=\frac{E}{E_{\text {sto }}}
$$

With $E$, the quantity of energy stored at a given time step (in Wh), i.e. the total energy available if there were no discharge losses and $E_{\text {sto }}$ the installed capacity (in Wh). 
The following equation defines the evolution of the state of energy of the storage device in function of the applied power during the period $[t ; t+\Delta t]$ and the auto-discharge, where $\Delta t$ is the time step.

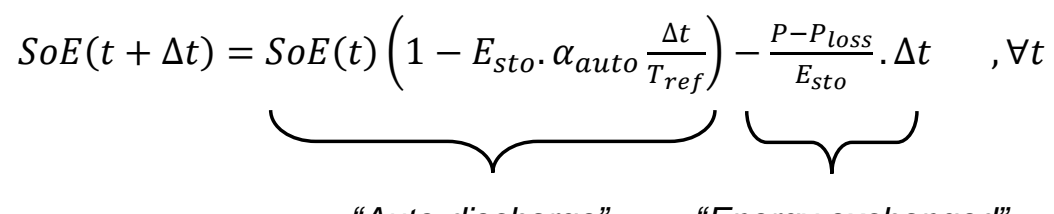

With $P_{\text {loss }}=\alpha_{\text {stor }} . P^{2}$

With $P$ the charge $(<0)$ or discharge $(>0)$ power, $\alpha_{\text {stor }}$ the loss coefficient, $\alpha_{\text {auto }}$ the autodischarge coefficient and $T_{\text {ref }}$ the auto-discharge reference period. During $T_{r e f}$, the storage system losses $100 * \alpha_{\text {auto }}$ percent of its energy.

The loss coefficient varies linearly with the state of energy:

- $\quad$ Charge : $\alpha_{\text {stor }}=\alpha_{c h}=\alpha_{c h, 0}+\alpha_{c h, v a r} . \operatorname{SoE}$

- Discharge : $\alpha_{\text {stor }}=\alpha_{d}=\alpha_{d, 0}-\alpha_{d, v a r} . S o E$

With $\alpha_{c h, 0}, \alpha_{c h, v a r}, \alpha_{d, 0}$ and $\alpha_{d, v a r}$ technological coefficients of the storage system.

3.3. Links between device models : sequential simulation

3.3.1. Simulation of a microgrid operation

The simulation's purpose is to determine the exchanged powers during the microgrid operation. The evolution of the power demand $P_{\text {demand }}$ and meteorological data are inputs for the whole simulation period.

Most of the time, simulations are performed on typical days and a time step chosen from minutes to hours, considering that it is representative of a longer operation period. In order to consider the seasonal variations of the consumption and meteorological data, twelve typical days are simulated in a row: one per month. To design the microgrid in the "worst case situation", each typical day is the average of all weekdays of the represented month. Indeed, the consumption is higher during the week. Using representative days allows to consider seasonal variations of the consumption and weather data while keeping a reasonable computation-time for the simulation (crucial when using a genetic algorithm). Moreover, in order to ensure the repeatability of the short-term period, several simulations are computed for each microgrid simulated (with different storage state of energy) in order to converge to a situation where the storage level remains constant (or higher) at the end of the simulation compared to the beginning. That being, authors make sure that the operation period, although short, can be repeated several times in a row.

Besides, it is still possible to perform a one-year simulation of a microgrid with hourly time steps when meteorological and electric demand data are available. Nevertheless, in the perspective of the implementation of these simulations in metaheuristic optimization algorithms, authors want to keep a short CPU-time and thus use simulations over twelve typical days of the year.

The simulation determines for each time step and for each device:

- $P_{\text {prod_for_cons }}$ : the production systems power used to balance demand ; 
- $\quad P_{\text {stor }}:$ the production systems power used for storage ;

- $\quad P_{\text {loss }}$ : the losses (Joule effect and (dis)charge losses);

- $\quad P_{\text {wasted }}$ : the available but unused power capacity.

\subsubsection{Priority order for production}

The sequential simulation means that, for each time step, generation and storage units are solicited one after the other in a specific order, that we call priority order. Many microgrids studies consider a fixed priority order during simulation and optimization processes. It is usually chosen in function of the marginal cost (merit order) [60]. Therefore, these studies do not assess the influence of various priority orders. Limiting the management parameters restricts the design space and prevents finding unconventional solutions.

Our microgrid model fixes a priority order for each simulation but offers the possibility to play on it as an optimization variable. As shown in Table 1, six priority orders have been defined here, based on technologies modelled. The choice has been made to limit the number of possibilities by considering the order fixed inside a category: uncontrollable production, controllable production and storage technologies. For example, with order $n^{\circ} 1$, renewable sources are solicited first to balance consumption - PV first and wind turbine second - then storage devices are discharged and finally controllable power plants produce the remaining energy needed.

Table 1: Description of the priority orders between technologies

\begin{tabular}{c|l|l|l|l|l|l|}
$\begin{array}{c}\text { Priority } \\
\text { order }\end{array}$ & $\mathbf{1}^{\text {st }}$ priority & $\mathbf{2}^{\text {nd }}$ priority & $\mathbf{3}^{\text {rd }}$ priority & $\mathbf{4}^{\text {th }}$ priority & $\mathbf{5}^{\text {th }}$ priority & $\mathbf{6}^{\text {th }}$ priority \\
\hline \hline 1 & PV & Wind turbine & Battery & PHES & Biomass & Gas \\
\hline 2 & PV & Wind turbine & Biomass & Gas & Battery & PHES \\
\hline 3 & Battery & PHES & Biomass & Gas & PV & Wind turbine \\
\hline 4 & Battery & PHES & PV & Wind turbine & Biomass & Gas \\
\hline 5 & Biomass & Gas & PV & Wind turbine & Battery & PHES \\
\hline 6 & Biomass & Gas & Battery & PHES & PV & Wind turbine \\
\hline
\end{tabular}

\subsubsection{Local management strategies of each technology}

Once solicited, a power unit can exchange power to balance consumption and/or to store its electricity. Local management strategies describe the operation of each power unit. Studies focusing on the operation of a specific microgrid usually explore different management strategies varying during the simulation to optimize the combination of a renewable energy with a storage device [61]. In design decision-making, the management strategy is usually constant during the simulation [27], [62]. As the strategy is chosen a priori, based on economical or environmental concerns, it is barely considered as a variable in design decisionmaking. Like for the priority order, using the management strategy as an optimization variable would extend the design space.

In this paper, local management strategies are constant during a simulation but this parameter is an optimization variable. Table 2 details the seven strategies defined (represented by an ID letter). They are based on two characteristic power levels: the maximal power for which a technology is dimensioned $\left(P_{\max }\right)$ and the optimal power $\left(P_{\text {opti }}\right)$ for which the technology's efficiency is the best (ratio between the output power and the consumed resources). A strategy defines the way a given technology is used depending on the situation. In other words, it defines if the technology can produce power to balance consumption and fill the storage 
devices, or only to balance consumption, and defines the maximal power. For example, a controllable gas power plant can be limited to the consumption supply whereas a wind turbine excess energy will be stored to avoid losing it. Depending on the technologies category (see Section 3.2), strategies may apply or not, as indicated in the last three columns of Table 2. For example, strategy $n^{\circ} \mathrm{A}$ can be applied to controllable power plants (CTRL) and to storage devices (STOR) but not to uncontrollable units (UNCTRL). We choose to apply the same strategy to all technologies of a category, which reduces the possible combinations to fourteen.

Table 2: Description of the local management strategies. The last three columns define the applicability of a strategy to the technologies' categories: controllable (CTRL), uncontrollable (UNCTRL) and storage technologies (STOR)

\begin{tabular}{c|l|c|c|c|}
$\begin{array}{c}\text { Strategy } \\
\text { ID }\end{array}$ & Local strategy description & CTRL & UNCTRL & STOR \\
\hline \hline A & Only balance consumption in the limit of $P_{\max }$ & $\mathrm{X}$ & & $\mathrm{X}$ \\
\hline $\mathrm{B}$ & Balance consumption and store in the limit of $P_{\max }$ & $\mathrm{X}$ & $\mathrm{X}$ & \\
\hline $\mathrm{C}$ & $\begin{array}{l}\text { Balance consumption in the limit of the } P_{\max } \text { and store } \\
\text { in the limit of } P_{\text {opti }}\end{array}$ & $\mathrm{X}$ & & \\
\hline $\mathrm{D}$ & Only balance consumption in the limit of $P_{\text {opti }}$ & $\mathrm{X}$ & & $\mathrm{X}$ \\
\hline $\mathrm{E}$ & Balance consumption and store in the limit of $P_{\text {opti }}$ & $\mathrm{X}$ & & \\
\hline $\mathrm{F}$ & $\begin{array}{l}\text { Produce at } P_{\text {opti }} \text { in the limit of the consumption and } \\
\text { storage capacities }\end{array}$ & $\mathrm{X}$ & & \\
\hline $\mathrm{G}$ & Store only in the limit of $P_{\text {opti }}$ & $\mathrm{X}$ & & \\
\hline
\end{tabular}

The control strategy of a microgrid (represented by an ID number) is a combination of the local strategies of each technologies' category. Table 3 summarizes all the possible combinations of local strategies (see Table 2) forming global microgrid strategies.

Table 3: Description of the fourteen microgrid global strategies, combinations of local strategies defined in Table 2. For each combination, the strategy applied to each category of technologies is indicated.

\begin{tabular}{|l|c|c|c|c|c|c|c|c|c|c|c|c|c|c|} 
Microgrid strategy ID & $\mathbf{1}$ & $\mathbf{2}$ & $\mathbf{3}$ & $\mathbf{4}$ & $\mathbf{5}$ & $\mathbf{6}$ & $\mathbf{7}$ & $\mathbf{8}$ & $\mathbf{9}$ & $\mathbf{1 0}$ & $\mathbf{1 1}$ & $\mathbf{1 2}$ & $\mathbf{1 3}$ & $\mathbf{1 4}$ \\
\hline \hline CTRL & $\mathrm{A}$ & $\mathrm{B}$ & $\mathrm{C}$ & $\mathrm{D}$ & $\mathrm{E}$ & $\mathrm{F}$ & $\mathrm{G}$ & $\mathrm{A}$ & $\mathrm{B}$ & $\mathrm{C}$ & $\mathrm{D}$ & $\mathrm{E}$ & $\mathrm{F}$ & $\mathrm{G}$ \\
\hline UNCTRL & $\mathrm{B}$ & $\mathrm{B}$ & $\mathrm{B}$ & $\mathrm{B}$ & $\mathrm{B}$ & $\mathrm{B}$ & $\mathrm{B}$ & $\mathrm{B}$ & $\mathrm{B}$ & $\mathrm{B}$ & $\mathrm{B}$ & $\mathrm{B}$ & $\mathrm{B}$ & $\mathrm{B}$ \\
\hline STOR & $\mathrm{A}$ & $\mathrm{A}$ & $\mathrm{A}$ & $\mathrm{A}$ & $\mathrm{A}$ & $\mathrm{A}$ & $\mathrm{A}$ & $\mathrm{D}$ & $\mathrm{D}$ & $\mathrm{D}$ & $\mathrm{D}$ & $\mathrm{D}$ & $\mathrm{D}$ & $\mathrm{D}$ \\
\hline
\end{tabular}

Figure 3 illustrates the sequential simulation process. During the process, we call destination the end-user of the produced electricity. It can be the consumer or one of the storage devices. For each technology in the priority order, the algorithm computes its available power $P_{\text {available_priority. }}$. The power that can be received by each destination (consumer $P_{\text {demand_remaining }}$ or storage device $P_{\text {storable_remaining }}$ ) is computed too. According to the power balance and the technology's strategy, it defines the power to produce/discharge to fill the destination's need. This power is then allocated between $P_{\text {produced_for_consumption }}, P_{\text {stor }}$, and $P_{\text {loss }}$. Before considering the next destination, the algorithm updates the remaining power demand, the storable power and the available power of the technology. Power allocation for this technology ends when there is no more available power or that all possible destinations have been tested. Remaining available power from a renewable source is wasted $\left(P_{\text {wasted }}\right)$ and the next technology in the priority order is investigated. The algorithm repeats this allocation process for each time step. Simulation ends when it has recorded all exchanged powers and storage states of energy. 


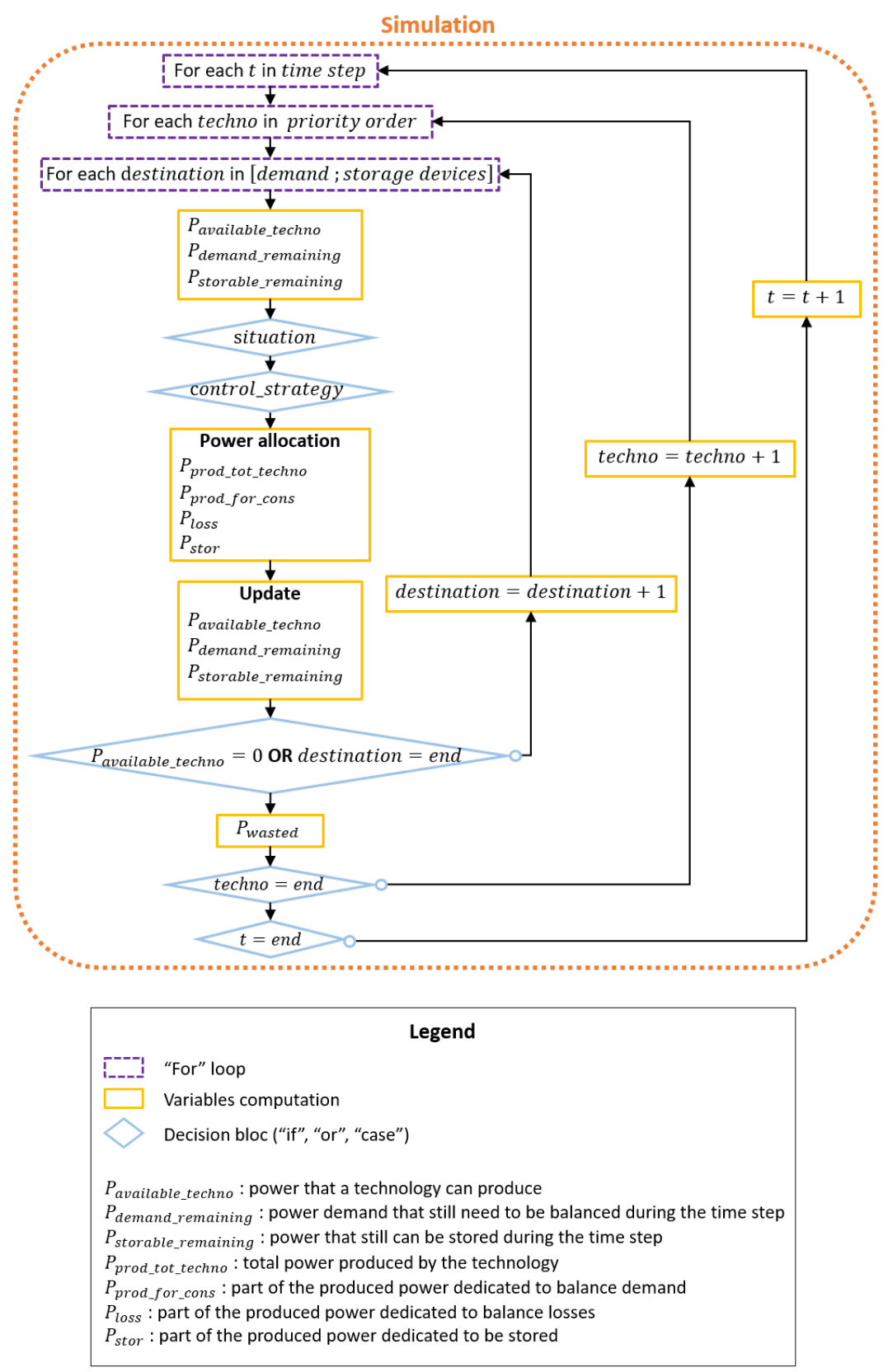

Figure 3: logical diagram of the sequential simulation process

The developed tool is able to study any electricity demand scenario (according to the phenomena considered by the models), considering the meteorological and geographical context of the territory. Figure 4 gives a simulation result example over twelve days with 90 minutes time steps to illustrate the capacities of the tool. It is composed of two graphs resulting from a simulation process with a fixed set of technological parameters, priority order and microgrid control strategy.

In Figure 4.a, the dotted line represents the power demand $P_{d e m}$. The bar chart shows the cumulated powers produced/discharged and stored by each unit, without the losses. The closer a technology is to the abscissa, the better it was ranked in the priority order.

- When $0<P<P_{\text {dem }}$, the bar chart represents the cumulated power produced or discharged $P_{\text {prod }}$ to balance consumption.

- When $P_{\text {dem }}<P$ it designates the cumulated power produced to store electricity $P_{\text {stor }}$. 
- When $P<0$, the bars shows the allocation of the stored power $-P_{\text {stor }}$ in the storage devices.

Figure 4.b shows the state of energy of the storage devices, in $\mathrm{kWh}$, at the end of each time step.

(a)

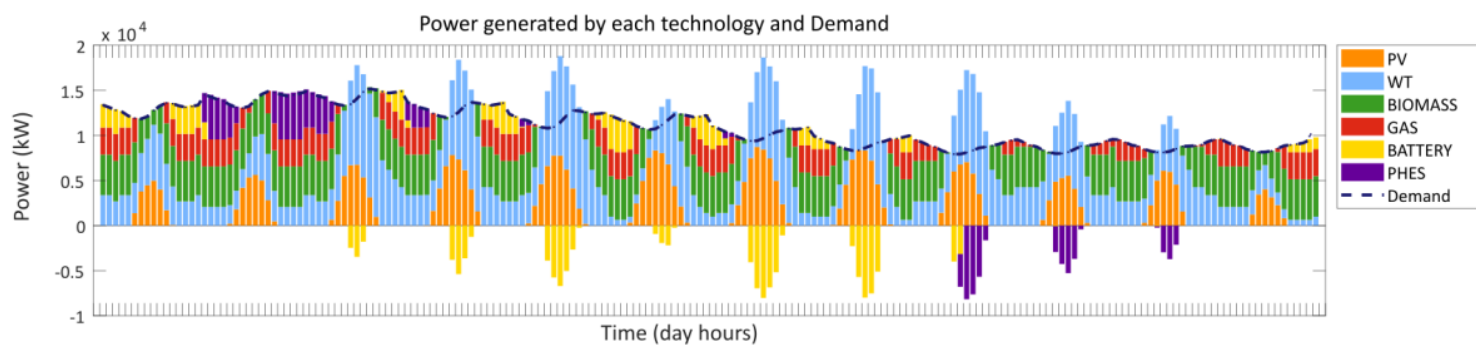

(b)

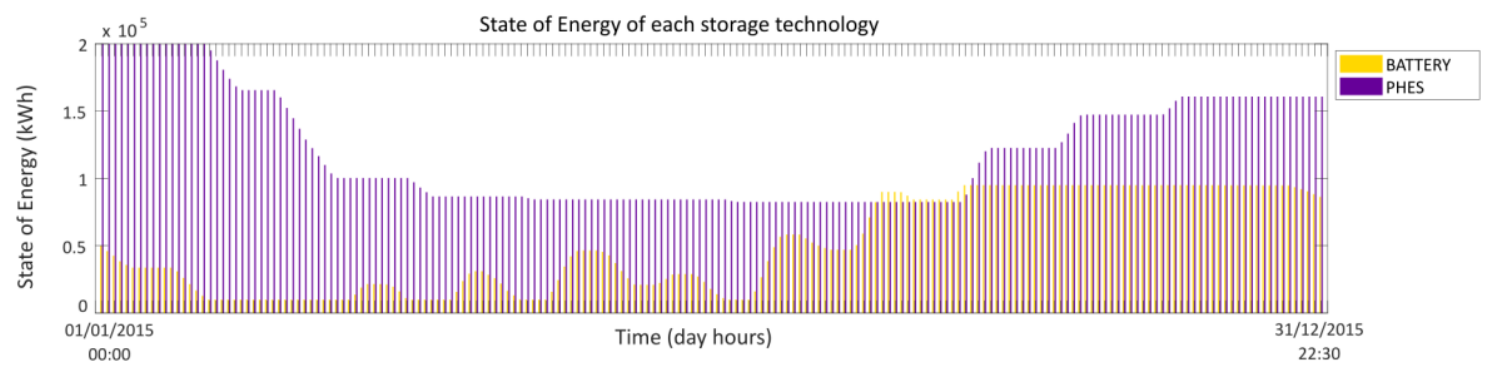

Figure 4: Twelve-days (one per month) sequential simulation of a microgrid - (a) Cumulated power ( $k W$ ) produced/stored along with the power demand of 6000 typical homes; (b) State of energy ( $k W h$ ) of the storage devices for each time step

Figure 4 allows to visualize the microgrid operation in terms of energy flows.

\subsection{Computation time}

With an Intel囚 Core ${ }^{\mathrm{TM}} \mathrm{i} 7-8850 \mathrm{H}$ CPU @2.60GHz, using Matlab software and taking into account six technologies, a twelve-days-simulation of a microgrid with 192 time steps of 90 minutes takes approximately 1.2 seconds.

\subsection{Performance indicators}

Following the simulation process, we want to assess the performances of a microgrid.

Figure 5.a represents the Input-Output diagram of the simulation. External inputs and design parameters are used to model technologies and simulate the microgrid operation. Simulation determines the exchanged powers. We define performance indicators using these powers.

Figure 5.b shows a non-exhaustive set of indicators computed: resources consumed, levelized cost of energy (LCOE), energy lost (via Joule effects especially), renewable energy wasted, energy autonomy, time autonomy and greenhouse gases emissions. Results from the simulation can be represented by this kind of radar plot, offering a visual way to compare these microgrids (see two illustrative examples on Figure 5.b). Indicators are normalized in the radar plot, the higher the better. Such visualization shows an insight of how compromises mixes may be illustrated. 
We choose to describe in the next sub-sections only three performance indicators that will be the objective-functions of the optimization. In order to represent the variety of concerns, there is one indicator per category - economic, environmental and technical.

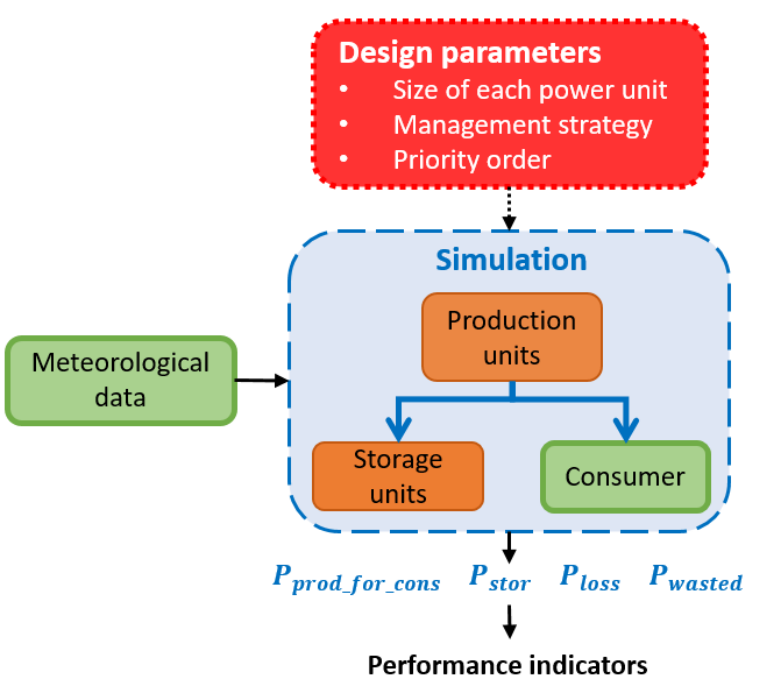

(a)

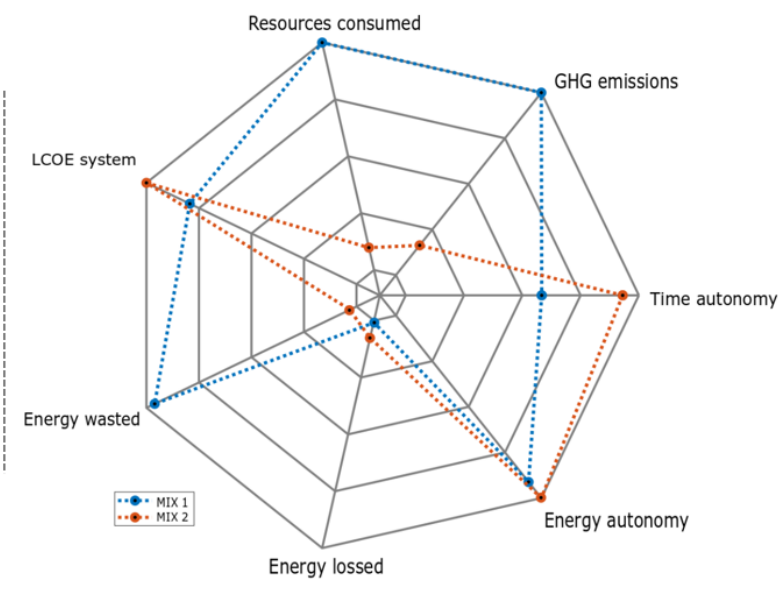

(b)

Figure 5: (a) Description of the simulation process that computes microgrid performance indicators from the exchanged powers between technologies; (b) Radar plot showing the performances of two microgrids according to seven indicators

\subsubsection{Economic indicator - LCOE}

One of the commonly used economic indicators in the energy field is the levelized cost of energy (LCOE, in $€ / \mathrm{kWh}$ ). It represents the total amount of money spent over the lifetime of a power plant divided by its produced energy, as described by Equation 9 [63].

$L C O E=\frac{\text { sum of discounted costs over lifetime }}{\text { sum of electrical energy produced over lifetime }}=\frac{\sum_{n=0}^{N} \frac{\left(I_{n}+O_{n}+M_{n}+D_{n}\right)}{(1+d)^{n}}}{\sum_{n=0}^{N} \frac{E_{n}}{(1+d)^{n}}}$

With $N$ the expected lifetime, $n$ the year, $I_{n}$ the investment costs, $O_{n}$ the operation costs, $M_{n}$ the maintenance costs, $D_{n}$ the residual value during year $n$ and $d$ the discount rate.

The indicator is simple to use, represents the complete cost of a power plant over its lifecycle and takes into account the currency discount over time. LCOE is only relevant to compare power plants at the same location, which is fine for the present use. However, it does not take into account the provided services like the frequency regulation or the reliability of the production and thus needs to be complemented by other indicators.

One major point of vigilance concerns the definition of the indicator and the data provenance. According to the source, different costs can be taken into account or not, such as the land lease, the insurance costs, the taxes or the carbon emissions. For data availability reasons, sources are different for the producers and storage systems. Investment costs of producers come from [64] and O\&M costs from [65]. The LCOE obtained can be compared to values taken from the Fifth report of the Intergovernmental Panel on Climate Change (IPCC) [46] to ensure a consistency between data. As storage costs are not evaluated in the IPCC report, all investment costs, operational costs and LCOE values for storage technologies come from [66]. LCOE value for the whole microgrid represents the sum of all lifecycle costs per technology divided by the provided energy by the microgrid, so the energy demand balanced. 
Find the best microgrid implies minimizing the LCOE value.

\subsubsection{Environmental indicator - greenhouse gases}

In this study, the greenhouse gases emissions' indicator (GHG emissions, in gCO2eq/kWh) represents the environmental impact of a microgrid. As for the LCOE (see Section 3.5.1), it is calculated over the expected lifetime of the power plant, depends on the location and requires consistency between data to ensure the same processes are taken into account. All the values related to the emissions during the construction of generation units have been taken from IPCC [46]. As storage emissions are not evaluated in the IPCC report, GHG emissions values over the lifecycle for storage technologies (related to installed capacity and exchanged energy during operation) come from [67].

Optimization process aims at minimizing the GHG emissions.

\subsubsection{Technical indicator - autonomy level}

Usual autonomy indicator represents the portion of time when demand is balanced by the local production [68], [69]. To assess more accurately the autonomy, we define an energy autonomy indicator $\left(L A_{\text {energy }}\right)$. It shows the portion of consumed energy produced by the microgrid over its lifetime (operation period).

$L A_{\text {energy }}=$ autonomy + excess

$$
\begin{aligned}
& \text { with autonomy }=\frac{E_{\text {produced_for_consumption }}}{E_{\text {demand }}} \\
& \text { excess }=\left\{\begin{array}{cl}
\frac{\left(S o E_{\text {final }}-S o E_{\text {initial }}\right) * E_{\text {sto }}}{E_{\text {demand }}} & \text { if } S o E_{\text {final }}>S o E_{\text {initial }} \\
0 & \text { if } S o E_{\text {final }} \leq S o E_{\text {initial }} \text { or autonomy } \neq 1
\end{array}\right.
\end{aligned}
$$

With $E_{\text {produced_for_consumption }}$ the total energy produced to balance consumption during the period, losses taken into account (in $\mathrm{kWh}$ ), $E_{\text {demand }}$ the total energy demand during the period (in $\mathrm{kWh}$ ), $S o E_{\text {initial }}$ the storage state of energy at the beginning of the simulation, $S o E_{\text {final }}$ at the end and $E_{\text {sto }}$ the storage capacity (in $\mathrm{kWh}$ ).

Excess variable represents storage excess at the end of the simulation, i.e. the global ability/robustness of the microgrid to respond to an extra demand. If $L A_{\text {energy }}$ is above one, it means that all consumption has been balanced and that the storage state of energy has increased during the period. The bigger $L A_{\text {energy }}$, the more robust the microgrid.

The indicator is calculated over the chosen simulation period. However, that period is often shorter than the real lifetime period (for computational time matters), which means the repeatability of the simulation must be checked in order to carefully define $L A_{\text {energy }}$. The relevance of the indicator depends on the variation of the storage state of energy between the beginning and the end of the simulation. For example, for a given energy storage at the beginning of the simulation, if the storage level is lower at the end of the simulation, there is a risk that the operation will not be repeatable. If it is higher, the autonomy indicator might be underestimated. Hence, an internal convergence loop computes the indicator again, updating the initial SoE values with the final values of the previous run. The loop only stops when the storage level remains constant between the beginning and the end of the simulation. This way, 
the energy autonomy calculated during the last simulation considers that the simulated period is repeatable.

When considered as an objective of the optimization process, the autonomy level is maximized. Due to algorithmic reasons, this technical indicator is modified in the optimization process so that its minimization corresponds to the maximization of the autonomy level. For this reason, authors will only talk about minimization of objectives in the rest of the article.

\section{Optimization problem and use of genetic algorithm}

\subsection{Principle of the genetic algorithm}

Genetic algorithms (GA) are inspired by the theory of evolution of species: a population of individuals, with their initial genes assembled into chromosomes, will evolve over generations to form a new population with different genes' values. In this study, an individual is a microgrid composed of genes (technological and management parameters) and a population is a set of microgrid that are not related. The best microgrids, i.e. the most adapted to their environment regarding the objective functions, are supposed to survive better to this evolution. The final population is composed of microgrids, characterized by their design parameters, which are all compromises between the objectives. Figure 6 describes the operation stages of the algorithm.

Two processes are involved in the modification of a microgrid characteristics (genes): crossover and mutation. A crossover occurs when two parent microgrids combine their characteristics: the child will be a combination of both parents' genes. For example in this case, a combination between the number of technologies of one parent with the management strategy of the other parent. In the GA, the crossover may happen between two random microgrids and concerns all the decision variables. Mutation is the random modification of a gene (i.e. a design parameter). In the NSGA-II algorithm, the usual crossover probability is $90 \%$ and the mutation probability is $10 \%$.

The GA uses the evaluation process detailed in Section 3 to assess the performances of all microgrids. In order to create the next generation, a selection process sorts the best compromises. New population has the same size as the initial one in a NSGA-II algorithm. Each generation implies a modification, evaluation and selection of the initial population to create a new one. The last generation is composed of Pareto-optimal solutions.

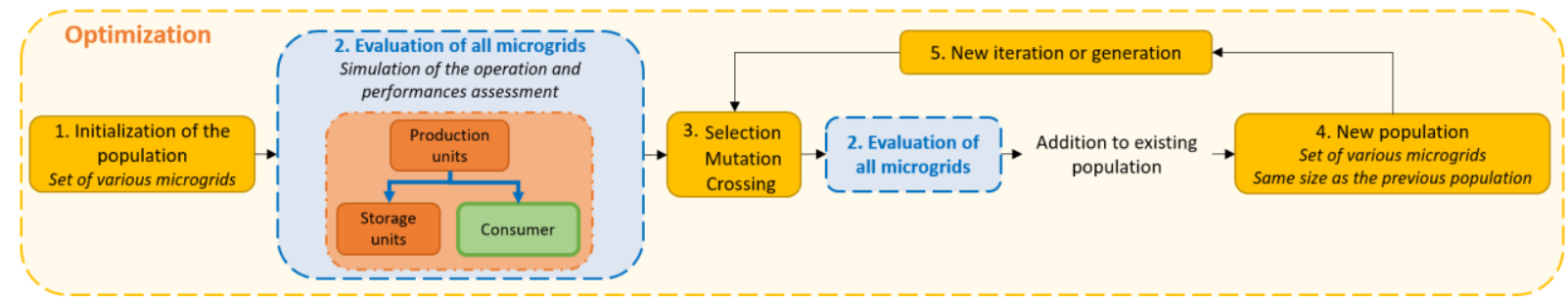

Figure 6 : Steps to process the genetic algorithm NSGA-II. Blue boxes represent the assessment of one microgrid (see Section 3), yellow boxes show the optimization steps and the yellow dotted line represents the overall process to find several microgrid compromises between various objectives

\subsection{Pareto-front reduction}

Convergence tests have shown that a substantial population size is required to perform an optimization with a huge design space (millions of possibilities). The final Pareto-front displays all microgrids in the final population (1000 in the case study). Therefore, it is hard to analyze 
for the decision-maker. A selection process helps reducing the number of relevant microgrids to display. We define tolerances for each variable and objective. The reduction process eliminates microgrids that are close in terms of performances unless one of their design parameters is different. Reduction of the number of relevant results allows reading and interpreting them and thus helps decision-makers to design their microgrid.

\section{Case study}

The territory (i.e. power demand and meteorological data), the design space (i.e. microgrid design parameters) and the objectives of the study (i.e. the economical, technical and environmental indicators we try to minimize) define this case study.

\subsection{Territory}

The development of a local microgrid is investigated for a 7000 typical homes town connected to the main grid and with no local power plants assumed. As explained in Section 3.3.1, we consider twelve typical days of the year 2015 (average of the weekdays of each month) and a 90-minute simulation time step. The inputs of the simulation are the power demand (see the evolution of the power demand represented by a dotted line in Figure 4.a) and the meteorological data - wind speed and solar irradiation - over the operation period.

Among the meteorological data, the solar irradiation is taken from the PVGIS dataset for Aixen-Provence location. The wind speed comes from a meteorological website Meteociel for Aixen-Provence too. Data are measured at a height of $10 \mathrm{~m}$ and then we extrapolate them at the turbine's height. Electrical consumption is deduced from the French transmission system operator's dataset (RTE). RTE provides national data corresponding to 35 million households. Consumption input is then a ratio of this data considering the population size of the territory. However, the purpose of this work is not to provide results for a specific case study but to analyze a methodology on a realistic dataset.

\subsection{Design space}

Table 4 lists all microgrid design potential parameters, also used as optimization decision variables. The range of each parameter, also in Table 4, limits the design space. The maximum of the range of power and energy available have been chosen in order to make it possible that one technology could fill the electricity demand by itself over the whole operating period. The chosen NSGA-II genetic algorithm works with continuous values. Discretization values have been chosen to found make sure that the solutions by the optimization algorithm are technologically different. These values have been carefully chosen to make sure they correspond to realistic data. The may be adapted to manufacturer's data in the case of a real industrial case study. Here, the wind turbine model relies on a real wind turbine's power curve. Other technologies are modelled with generic models [70]. Therefore, their range of values and discretization are theoretical. The battery capacity is considered as a global storage capacity. It can be realized with battery containers, e.g. $500 \mathrm{kWh}$-battery containers with a maximal charge and discharge power of $500 \mathrm{~kW}$. The discretization is bigger than $500 \mathrm{kWh}$ to reduce the number of possible combinations. 
Table 4: List of the decision variables with the range of their values and the tolerance associated

\begin{tabular}{l|l|l|} 
Decision variables & Range & Discretization values \\
\hline \hline Number of wind turbines (Vestas V90 -2MW) & $0-15$ & 1 turbine \\
\hline Surface of PV panels & $0-300,000 \mathrm{~m}^{2}$ & $15000 \mathrm{~m}^{2}$ \\
\hline Installed power of biomass power plant & $0-15 \mathrm{MW}$ & $750 \mathrm{~kW}$ \\
\hline Installed power of gas power plant & $0-15 \mathrm{MW}$ & $750 \mathrm{~kW}$ \\
\hline Battery capacity & $0-1600 \mathrm{MWh}$ & $80 \mathrm{MWh}$ \\
\hline $\begin{array}{l}\text { Pumped hydroelectric energy storage (PHES) } \\
\text { capacity }\end{array}$ & $0-1600 \mathrm{MWh}$ & $80 \mathrm{MWh}$ \\
\hline Microgrid control strategy & 14 combinations & 1 \\
\hline Priority order & 6 combinations & 1 \\
\hline
\end{tabular}

Following convergence tests, for this case study, we have set the size of the initial population to 1000 individuals, allowing a good variety of microgrids and ensuring a convergence of the algorithm avoiding local minimum. Convergence tests have shown that 300 generations are sufficient to stabilize the final population. This number is consistent with other observations [71]. The number of microgrids analyzed by the algorithm is thus inferior to 300,000 . Considering the range of values for each parameter as shown in Table 4, the total number of possible combination would be $1,4.10^{9}$.

\subsection{Objectives}

This study considers different categories of impacts: economic, environmental and technical. Optimization objective-functions are the performance indicators presented in Section 3.5. The optimization process minimizes three objective-functions: the LCOE, the GHG emissions and the energy dependence to the main grid. Another way to represent the economic indicator is the lifecycle cost. It is the product of the LCOE by the energy produced during the simulated period. The advantage is a better discrimination between similar microgrids according to their operation.

Two optimizations are performed, one with LCOE and GHG emissions as objectives and the other with lifecycle cost and energy autonomy.

\section{Results}

This section presents the results of two optimization processes with different pairs of objectives. Representation of the final population takes the form of a Pareto-front with one objective on each axis. Each point of the front represents one microgrid solution of the optimization. The lower the value, the better the indicator.

Optimization is performed in approximately $35 \mathrm{~h}$ depending on the nature and number of objectives.

\subsection{LCOE and GHG emissions}

Figure 7 shows the Pareto-front of the twenty-five selected microgrids (see Section 4.2) after an optimization with LCOE and greenhouse gases (GHG) emissions as objectives. In order to ensure a minimal autonomy level, microgrids analyzed during the optimization have been 
constrained to at least $100 \%$ energy autonomy. The cost values are displayed on the abscissa and the GHG emissions on the ordinate. Microgrids on the top-left of the figure have low cost and high emissions, whereas the ones on the bottom-right have lower emissions but are more expensive.

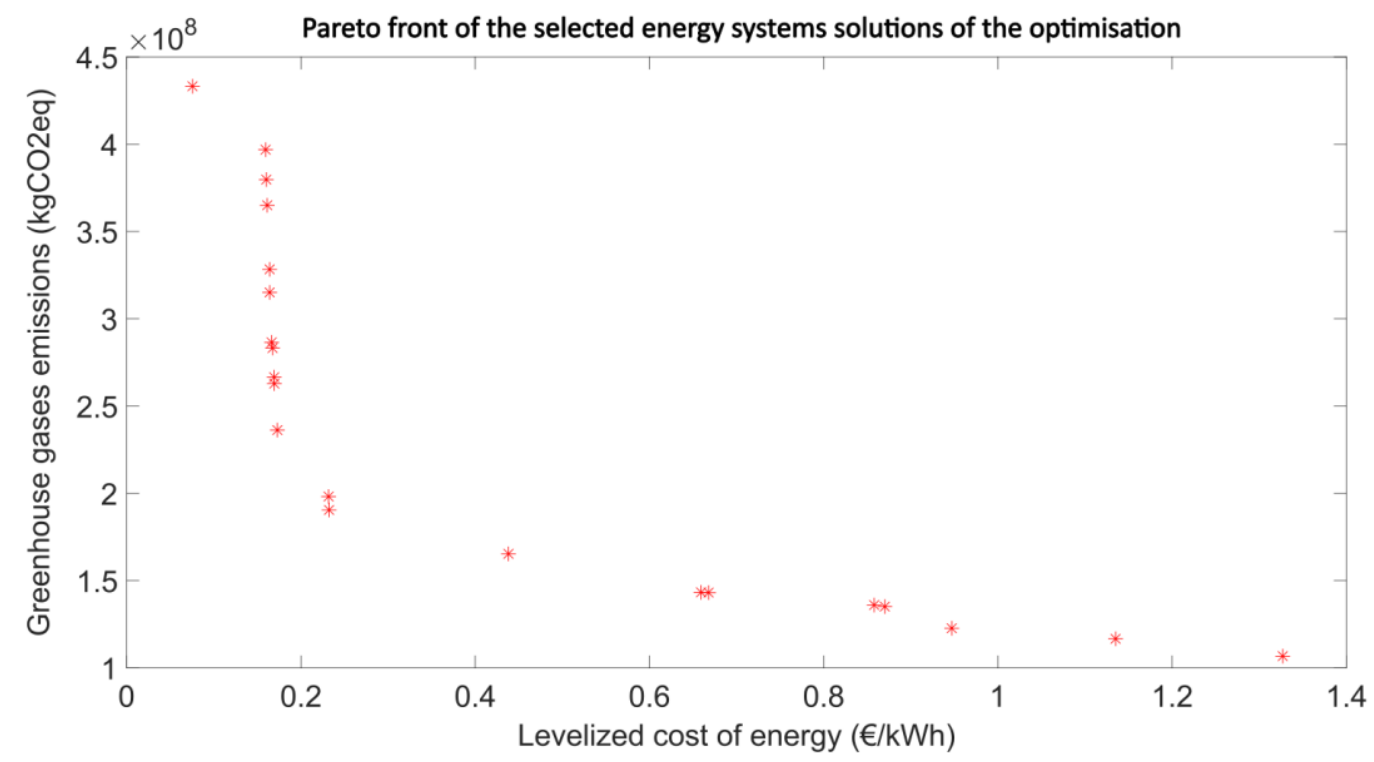

Figure 7: Pareto-front with the selected solutions of the LCOE-GHG emissions optimization process

Table 5 indicates the parameters' values of these microgrids. Each line is a microgrid solution of the optimization, with the microgrid ID in the first column, the value of all other parameters in the following height columns and the performances values in the three final columns. Table 5 also displays the energy autonomy indicator but it is not an objective-function of the optimization. Parameters' ranges are indicated in Section 5.2.

Table 5: Parameters values from thirty-eight selected energy mixes after the optimization process, trade-offs between economic (LCOE) and environmental (GHG emissions) objectives

\begin{tabular}{|c|c|c|c|c|c|c|c|c|c|c|c|}
\hline ID & $\begin{array}{l}\text { Number } \\
\text { of WT }\end{array}$ & $\begin{array}{c}\text { PV } \\
\text { surface } \\
\left(\mathrm{m}^{2}\right)\end{array}$ & $\begin{array}{c}\text { Biomass } \\
\text { installed } \\
\text { power } \\
\text { (MW) }\end{array}$ & $\begin{array}{c}\text { Gas } \\
\text { installed } \\
\text { power } \\
(\mathrm{MW})\end{array}$ & $\begin{array}{l}\text { Battery } \\
\text { capacity } \\
\text { (MWh) }\end{array}$ & $\begin{array}{c}\text { PHES } \\
\text { capacity } \\
\text { (MWh) }\end{array}$ & $\begin{array}{c}\text { Microgrid } \\
\text { control } \\
\text { strategy }\end{array}$ & $\begin{array}{l}\text { Priority } \\
\text { order }\end{array}$ & $\begin{array}{l}\text { LCOE } \\
(€ / k W h)\end{array}$ & $\begin{array}{c}\text { GHG } \\
\text { emissions } \\
\text { (kgCO2eq) }\end{array}$ & $\begin{array}{c}\text { Autonomy } \\
\text { (\% of } \\
\text { energy } \\
\text { demand) }\end{array}$ \\
\hline$\overline{\mathrm{LG1}}$ & - & 45000 & 12,0 & 3,8 & - & - & $\overline{9}$ & $\overline{6}$ & 0,076 & 433230 & $100 \%$ \\
\hline LG2 & 12 & 45000 & 1,5 & 9,0 & 80 & - & 10 & 2 & 0,159 & 396902 & $101 \%$ \\
\hline LG3 & 13 & 45000 & 1,5 & 9,0 & 80 & - & 10 & 2 & 0,160 & 379763 & $101 \%$ \\
\hline LG4 & 14 & 45000 & 1,5 & 9,0 & 80 & - & 10 & 2 & 0,161 & 365049 & $101 \%$ \\
\hline LG5 & 13 & 45000 & 3,0 & 7,5 & 80 & - & 10 & 2 & 0,163 & 335368 & $101 \%$ \\
\hline LG6 & 12 & 45000 & 3,8 & 6,8 & 80 & - & 10 & 2 & 0,164 & 328348 & $101 \%$ \\
\hline LG7 & 14 & 30000 & 3,0 & 7,5 & 80 & - & 10 & 2 & 0,164 & 315125 & $101 \%$ \\
\hline LG8 & 15 & 30000 & 3,8 & 6,8 & 80 & - & 10 & 2 & 0,166 & 286497 & $101 \%$ \\
\hline LG9 & 13 & 45000 & 5,3 & 5,3 & 80 & - & 10 & 2 & 0,167 & 283272 & $101 \%$ \\
\hline LG10 & 12 & 45000 & 6,0 & 4,5 & 80 & - & 10 & 2 & 0,168 & 279522 & $101 \%$ \\
\hline LG11 & 14 & 45000 & 5,3 & 5,3 & 80 & - & 10 & 2 & 0,168 & 274879 & $101 \%$ \\
\hline LG12 & 13 & 45000 & 7,5 & 3,0 & 80 & - & 10 & 2 & 0,171 & 248998 & $101 \%$ \\
\hline LG13 & 15 & 45000 & 6,8 & 3,8 & 80 & - & 10 & 2 & 0,171 & 246849 & $101 \%$ \\
\hline LG14 & 14 & 45000 & 8,3 & 2,3 & 80 & - & 10 & 2 & 0,173 & 238197 & $101 \%$ \\
\hline LG15 & 15 & 45000 & 9,0 & 0,8 & 80 & - & 10 & 2 & 0,175 & 226834 & $101 \%$ \\
\hline LG16 & 14 & - & 8,3 & 2,3 & - & 80 & 8 & 2 & 0,232 & 198204 & $101 \%$ \\
\hline LG17 & 15 & - & 8,3 & 1,5 & - & 80 & 8 & 2 & 0,232 & 190508 & $101 \%$ \\
\hline LG18 & 15 & - & 6,0 & - & - & 160 & 8 & 2 & 0,438 & 165365 & $102 \%$ \\
\hline LG19 & 15 & - & 3,8 & - & - & 240 & 8 & 2 & 0,659 & 143320 & $100 \%$ \\
\hline LG20 & 14 & - & 3,8 & - & - & 240 & 8 & 2 & 0,668 & 143175 & $100 \%$ \\
\hline LG21 & 15 & - & 3,0 & - & - & 320 & 8 & 2 & 0,858 & 136040 & $100 \%$ \\
\hline LG22 & 14 & - & 3,0 & - & - & 320 & 8 & 2 & 0,870 & 135153 & $100 \%$ \\
\hline LG23 & 15 & - & 7,5 & - & - & 320 & 8 & 1 & 0,947 & 122730 & $100 \%$ \\
\hline LG24 & 15 & - & 5,3 & 0,8 & - & 400 & 8 & 1 & 1,132 & 119419 & $100 \%$ \\
\hline LG25 & 15 & - & 3,8 & - & - & 480 & 8 & 1 & 1,327 & 106766 & $100 \%$ \\
\hline
\end{tabular}




\subsection{LCOE and autonomy}

Figure 8 shows the Pareto-front of the thirty selected microgrids after an optimization with LCOE and energy autonomy as objectives. Graph shows the cost values on the abscissa and the autonomy ones on the ordinate. Microgrids on the top-left of the figure have low cost and are not autonomous, whereas the ones on the bottom-right are fully autonomous but are more expensive.

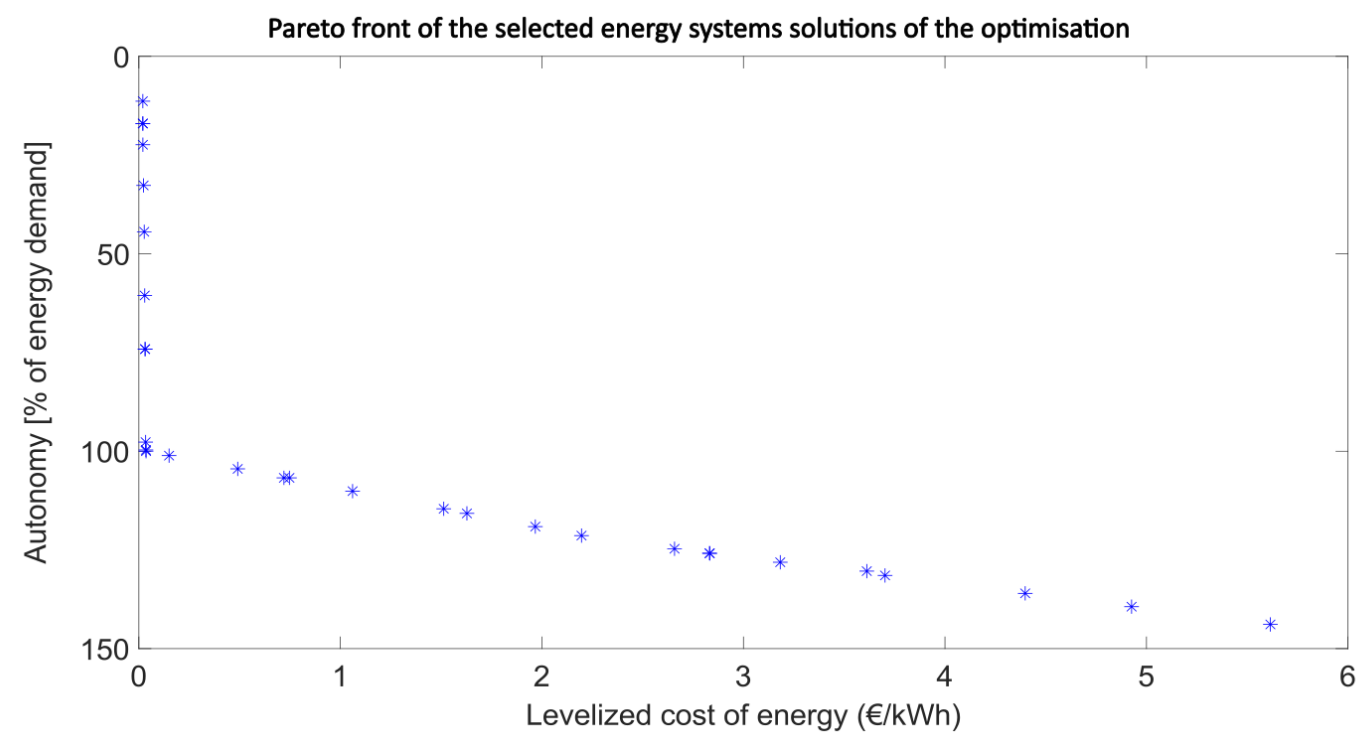

Figure 8: Pareto-front with the selected solutions of the LCOE-autonomy optimization process

Table 6 indicates the parameters' values of the microgrid solutions. Last column represents the GHG emissions indicator even though it is not an optimization objective.

Figure 9 graphically represents the microgrids parameters from Table 6 . For the three bar charts, the abscissa shows the thirty selected solutions ranked based on their id. In Figure 9.a, each microgrid is defined by four bars representing the values of installed power, in W, of the four considered technologies: wind turbines, PV panels, biomass and gas power plants. In Figure 9.b only two bars are assigned to a microgrid: the battery and the PHES installed storage capacity, in kWh. Eventually Figure 9.c describes the chosen priority order (see Table 1) and control strategy (see Table 3 ) for each microgrid.

(a)

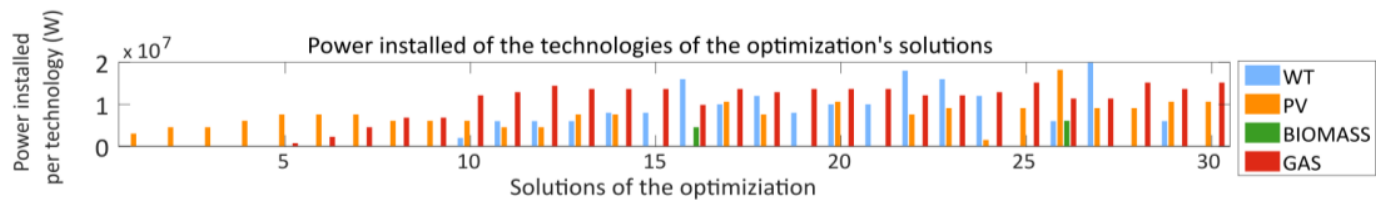

(b)

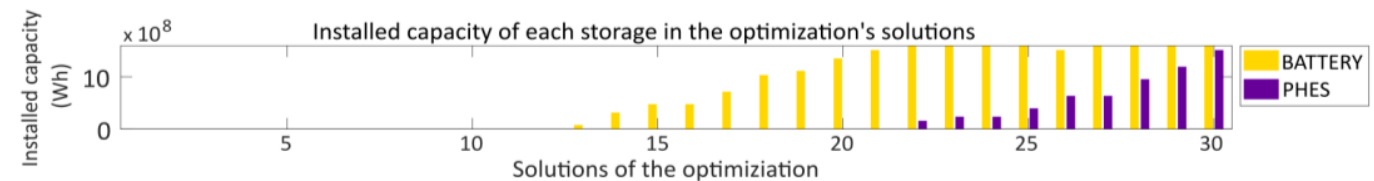

(c)

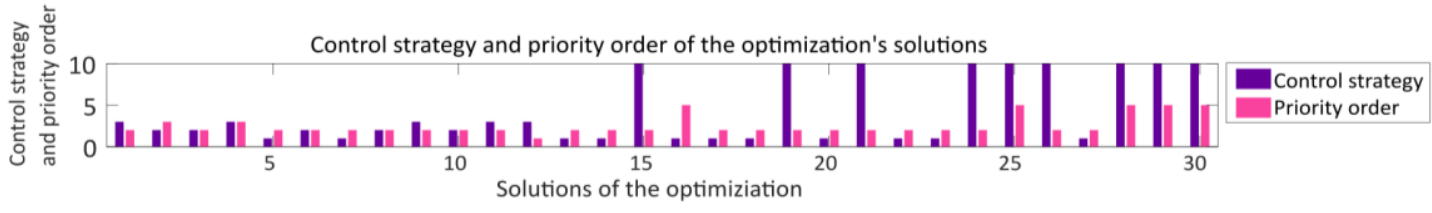

Figure 7: for each Pareto-optimal solution of the reduced final population, (a) power installed per technology in W, (b) installed storage capacity in $\mathrm{kWh}$, (c) chosen control strategy and priority order number 
Table 6: Parameters values from thirty selected energy mixes after the optimization process, trade-offs between economic (LCOE) and technical (energy autonomy) objectives

\begin{tabular}{|c|c|c|c|c|c|c|c|c|c|c|c|}
\hline ID & $\begin{array}{c}\text { Num } \\
\text { ber } \\
\text { of } \\
\text { WT }\end{array}$ & $\begin{array}{c}\text { PV } \\
\text { surface } \\
\left(\mathrm{m}^{2}\right)\end{array}$ & $\begin{array}{c}\text { Biomass } \\
\text { installed } \\
\text { power } \\
(\mathrm{MW})\end{array}$ & $\begin{array}{c}\text { Gas } \\
\text { installed } \\
\text { power } \\
(\mathrm{MW})\end{array}$ & $\begin{array}{c}\text { Battery } \\
\text { capacity } \\
\text { (MWh) }\end{array}$ & $\begin{array}{c}\text { PHES } \\
\text { capacity } \\
\text { (MWh) }\end{array}$ & $\begin{array}{c}\text { Microgrid } \\
\text { control } \\
\text { strategy }\end{array}$ & $\begin{array}{c}\text { Priority } \\
\text { order }\end{array}$ & $\begin{array}{c}\text { LCOE } \\
(€ / k W h)\end{array}$ & $\begin{array}{c}\text { Autonomy } \\
\text { (\% of } \\
\text { energy } \\
\text { demand) }\end{array}$ & $\begin{array}{c}\text { GHG } \\
\text { emissions } \\
\text { (tons } \\
\text { cO2eq) }\end{array}$ \\
\hline LA1 & - & 30000 & - & - & - & - & 3 & 2 & 0,020 & $11 \%$ & 34319 \\
\hline LA2 & - & 45000 & - & - & - & - & 2 & 3 & 0,020 & $17 \%$ & 51478 \\
\hline LA3 & - & 45000 & - & - & - & - & 2 & 2 & 0,020 & $17 \%$ & 51478 \\
\hline LA4 & - & 60000 & - & - & - & - & 3 & 3 & 0,020 & $22 \%$ & 68299 \\
\hline LA5 & - & 75000 & - & 0,8 & - & - & 1 & 2 & 0,023 & $33 \%$ & 158159 \\
\hline LA6 & - & 75000 & - & 2,3 & - & - & 2 & 2 & 0,027 & $44 \%$ & 302533 \\
\hline LA7 & - & 75000 & - & 4,5 & - & - & 1 & 2 & 0,029 & $61 \%$ & 502517 \\
\hline LA8 & - & 60000 & - & 6,8 & - & - & 2 & 2 & 0,031 & $74 \%$ & 708350 \\
\hline LA9 & - & 60000 & - & 6,8 & - & - & 3 & 2 & 0,031 & $74 \%$ & 708350 \\
\hline LA10 & 1 & 60000 & - & 12,0 & - & - & 2 & 2 & 0,034 & $98 \%$ & 940866 \\
\hline LA11 & 3 & 45000 & - & 12,8 & - & - & 3 & 2 & 0,035 & $100 \%$ & 869767 \\
\hline LA12 & 3 & 45000 & - & 14,3 & - & - & 3 & 1 & 0,036 & $100 \%$ & 878237 \\
\hline LA13 & 3 & 75000 & - & 13,5 & 80 & - & 1 & 2 & 0,150 & $101 \%$ & 850179 \\
\hline LA14 & 4 & 75000 & - & 13,5 & 320 & - & 1 & 2 & 0,490 & $104 \%$ & 834098 \\
\hline LA15 & 4 & - & - & 13,5 & 480 & - & 10 & 2 & 0,720 & $107 \%$ & 1079343 \\
\hline LA16 & 8 & - & 4,5 & 9,8 & 480 & - & 1 & 5 & 0,747 & $107 \%$ & 1065993 \\
\hline LA17 & 5 & 105000 & - & 13,5 & 720 & - & 1 & 2 & 1,061 & $110 \%$ & 845063 \\
\hline LA18 & 6 & 75000 & - & 12,8 & 1040 & - & 1 & 2 & 1,513 & $115 \%$ & 844886 \\
\hline LA19 & 4 & - & - & 13,5 & 1120 & - & 10 & 2 & 1,628 & $116 \%$ & 1269577 \\
\hline LA20 & 5 & 105000 & - & 13,5 & 1360 & - & 1 & 2 & 1,967 & $119 \%$ & 930262 \\
\hline LA21 & 5 & - & - & 13,5 & 1520 & - & 10 & 2 & 2,197 & $121 \%$ & 1312602 \\
\hline LA22 & 9 & 75000 & - & 12,0 & 1600 & 160 & 1 & 2 & 2,658 & $125 \%$ & 821329 \\
\hline LA23 & 8 & 90000 & - & 12,0 & 1600 & 240 & 1 & 2 & 2,831 & $126 \%$ & 860986 \\
\hline LA24 & 6 & 15000 & - & 12,8 & 1600 & 240 & 10 & 2 & 2,833 & $126 \%$ & 1257026 \\
\hline LA25 & - & 90000 & - & 15,0 & 1600 & 400 & 10 & 5 & 3,183 & $128 \%$ & 1586208 \\
\hline LA26 & 3 & 180000 & 6,0 & 11,3 & 1520 & 640 & 10 & 2 & 3,612 & $130 \%$ & 1075336 \\
\hline LA27 & 10 & 90000 & - & 11,3 & 1600 & 640 & 1 & 2 & 3,703 & $131 \%$ & 819019 \\
\hline LA28 & 0 & 90000 & - & 15,0 & 1600 & 960 & 10 & 5 & 4,398 & $136 \%$ & 1643063 \\
\hline LA29 & 3 & 105000 & - & 13,5 & 1600 & 1200 & 10 & 5 & 4,926 & $139 \%$ & 1599486 \\
\hline LA30 & 0 & 105000 & - & 15,0 & 1600 & 1520 & 10 & 5 & 5,615 & $144 \%$ & 1694613 \\
\hline
\end{tabular}

\section{Discussion}

This section analyzes the results of the optimization processes. Both results show the interest of the tool to find various efficient microgrids following several indicators and to increase the decision-making autonomy. First, results of the optimization with LCOE and GHG emissions as objectives show how the diversity of performances the tool can find improves the decisionmaking autonomy. Second, the optimization with LCOE and energy autonomy illustrates the variety of parameters in the results. Eventually, an analysis of this last optimization underlines the proximity in terms of performances of microgrids with different parameters.

\subsection{Performances' diversity}

Results of the first optimization with LCOE and GHG emissions as objectives show the developed tool' ability to find several microgrids that are compromises between economic and environmental performances. Results are well distributed in the performance space, with cheap but pollutant microgrids at the top-left and expensive but cleaner ones at the bottomright. The tool suggests several solutions but the final choice is up to the decision-maker. The variety of results allows to satisfy users with different priorities. Moreover, the interest of having various microgrids suggested is that one can modify its priorities. For example, microgrids $n^{\circ}$ LG17 and $n^{\circ}$ LG18 (see Table 5) have close emissions values but microgrid $n^{\circ}$ LG18 is almost twice as expensive as microgrid $n^{\circ}$ LG17. When a substantial improvement of one objective implies a small deterioration of the other, it can lead the decision-maker to consider the alternative. This opportunity is only possible with a non-weighted $\mathrm{MO}$ optimization exploring the entire design space, whereas it would depend on the weights of the different objectives in 
other methods. With this approach, microgrid design does not rely on a design space restrained to usual solutions but on decision-making rationale [38].

\subsection{Parameters' diversity}

Results of the second optimization with LCOE and energy autonomy as objectives still present a good performance variety. The Pareto-front displays cheap but partially autonomous microgrids (top-left) and others expensive but fully autonomous (bottom-right), ensuring robustness towards external event when autonomy goes up to $100 \%$. Besides, microgrids in the front present diversified parameters. This diversity of solutions allows considering microgrids with storage or not, with a high share of renewable sources or mostly controllable ones and different management strategies and priority order. The decision-maker can select afterward a microgrid according to the optimization's objectives but also according to other discriminating criteria that may not be objectives of the optimization strictly speaking. One can consider other performance indicators (see Section 3.5) or a criterion linked to the parameters' values (social acceptance of the wind turbines for example). Compared to methods restraining the design space a priori, this shows the ability of the developed tool to increase the decisionmaking autonomy and opens to unconventional solutions.

For example, microgrid $n^{\circ} \mathrm{LA} 18$ (see Table 6 ) differs from microgrid $n^{\circ} \mathrm{LA} 19$ by the presence of PV panels, the number of wind turbines and the level of gas installed power and battery capacity. This way, microgrid $n^{\circ}$ LA 18 is cheaper by $7 \%$ compared to microgrid $n^{\circ} L A 19$ with a similar autonomy. Apart from the objectives, one way to distinguish the two microgrids is to compare their number of wind turbines, knowing that their social acceptance is a challenge, or their GHG emissions (microgrid nLA18 being less pollutant).

These two microgrids also highlight the importance of the control strategy choice. Microgrid $n^{\circ}$ LA18 is driven by the control strategy $n^{\circ} 1$, which means that both controllable and storage technologies are used to balance the power demand but are not allowed to store energy. Microgrid $n^{\circ}$ LA19 is driven by strategy $n^{\circ} 10$, which means that the controllable technologies are allowed to store. This difference in control strategy results in two microgrids composed of different technologies, both Pareto-optimal solutions. Thus, considering control strategies as a parameter of the optimization also widen the design space.

\subsection{Different Microgrid with similar performances}

Interestingly, some solutions of the previous optimization show similar performances but different parameters. For example, microgrids $n^{\circ} \mathrm{LA} 15$ and $\mathrm{n}^{\circ} \mathrm{LA} 16$ (see Table 6 ) have close objectives but the first one favors wind turbines production whereas the other favors controllable power plants production. If their performances match with the decision-maker's priority, it will give additional choice for the selection step. Besides, this feature widens the field of possibilities and offers unconventional solutions to the user, increasing the decision-making.

This particular example underlines again the advantage of multi-objective optimization to give multiple choices to the user for the same effective results. 


\section{Conclusion}

The presented work focuses on the design of microgrids. In order to improve the decisionmaking autonomy, the developed tool is able to find various microgrid compromises between economic, technical and environmental objectives. The main steps to achieve this decisionsupport are the physical modeling of microgrids, the simulation of their operation, the evaluation of performance indicators and finally the use of this process in a metaheuristic optimization algorithm.

The first contribution of the authors is to consider both technological and management parameters in the microgrid design parameters and to use sequential simulation to assess several categories of indicators (economical, technical and environmental). Physical modelling of a microgrid relies on technological parameters. Choice has been made to consider the influence of hourly physical phenomena on the performances. For that, a sequential simulation assesses the microgrid behavior according to two management parameters: priority order and control strategy. The tool is able to simulate the operation of a wide range of microgrids in any local territory (defined by geographical and meteorological data) and assess its performances. Its modularity allows to consider new technologies, management strategies and performance indicators in the simulation. Besides, the computation-time is sufficiently small for its use inside a metaheuristic optimization loop.

The second contribution of this article is the use of a non-weighted multi-objective optimization process, using genetic algorithm NSGA-II. It enables to find several microgrids adapted to a local electricity demand, finding the best compromises between economical, technical and environmental indicators. The use of metaheuristic methods without a prior weighting of the indicators increases the design space. Optimizations' results display the possibility of proposing various solutions with a wide range of performances and characteristics. It also underlines situations where two much different microgrids can have close performances. This allows the decision-maker to select microgrids afterward according to its own criteria and opens to a wider variety of microgrid possibilities.

The main novelty of this article is the consideration of management parameters in the multiobjective, non-weighted, optimization of microgrids design in order to explore a wider design space. On a theoretical level, this work shows the interest of the non-weighted optimization approach to find various trade-offs, including microgrids with different parameters but close performances. Moreover, considering management strategies as a parameter of the optimization extend the design space. On a practical point of view, the developed tool will be able to provide several feasible solutions, and especially unconventional ones, to local decision-makers. In addition, local decision-makers can design microgrids according to their priorities without having to master several performances assessment software.

Beyond the present article, an objective of this work is to question current habits and business rules to find innovative microgrids. This implies using detailed technological parameters as decision variables and analyzing the design space limits. This will be done in a future work. Moreover, a perspective of the present work is the improvement of the repeatability of the simulated period in order to ensure that the computed indicators are representative of a longterm operation.

\section{Acknowledgment}

This work was supported by the Region Provence-Alpes-Côte d'Azur, France. 


\section{References}

[1] T. Ackermann, G. Andersson, et L. Söder, " Distributed generation: a definition », Electric Power Systems Research, vol. 57, n 3, p. 195-204, April 2001, doi: 10.1016/S0378-7796(01)00101-8.

[2] A. S. Brouwer, M. van den Broek, W. Zappa, W. C. Turkenburg, et A. Faaij, « Least-cost options for integrating intermittent renewables in low-carbon power systems ", Applied Energy, vol. 161, p. 48-74, Jan. 2016, doi: 10.1016/j.apenergy.2015.09.090.

[3] A. Hirsch, Y. Parag, et J. Guerrero, " Microgrids: A review of technologies, key drivers, and outstanding issues ", Renewable and Sustainable Energy Reviews, vol. 90, p. 402-411, Jul. 2018, doi: 10.1016/j.rser.2018.03.040.

[4] D. E. Olivares, A. Mehrizi-Sani, A.H. Etemadi, C.A. Cañizares, R. Iravani, M. Kazerani et al., " Trends in Microgrid Control », IEEE Transactions on Smart Grid, vol. 5, n 4, p. 1905-1919, Jul. 2014, doi: 10.1109/TSG.2013.2295514.

[5] M. F. Zia, E. Elbouchikhi, et M. Benbouzid, « Microgrids energy management systems: A critical review on methods, solutions, and prospects ", Applied Energy, vol. 222, p. 1033-1055, Jul. 2018, doi: 10.1016/j.apenergy.2018.04.103.

[6] D. T. Ton et M. A. Smith, "The U.S. Department of Energy's Microgrid Initiative ", The Electricity Journal, vol. 25, nº 8, p. 84-94, Oct. 2012, doi: 10.1016/j.tej.2012.09.013.

[7] A. J. Aristizábal, J. Herrera, M. Castaneda, S. Zapata, D. Ospina, et E. Banguero, « A new methodology to model and simulate microgrids operating in low latitude countries ", Energy Procedia, vol. 157, p. 825-836, Jan. 2019, doi: 10.1016/j.egypro.2018.11.248.

[8] S. A. Arefifar et Y. A. I. Mohamed, « DG Mix, Reactive Sources and Energy Storage Units for Optimizing Microgrid Reliability and Supply Security ", IEEE Transactions on Smart Grid, vol. 5, $\mathrm{n}^{\circ}$ 4, p. 1835-1844, Jul. 2014, doi: 10.1109/TSG.2014.2307919.

[9] M. Ross, C. Abbey, F. Bouffard, et G. Jos, « Multiobjective Optimization Dispatch for Microgrids With a High Penetration of Renewable Generation ", IEEE Transactions on Sustainable Energy, vol. 6 , $n^{\circ} 4$, p. $1306-1314$, Oct. 2015, doi: 10.1109/TSTE.2015.2428676.

[10] A. D. Hawkes et M. A. Leach, « Modelling high level system design and unit commitment for a microgrid ", Applied Energy, vol. 86, n 7, p. 1253-1265, Jul. 2009, doi: 10.1016/j.apenergy.2008.09.006.

[11] Z. Zeng, R. Zhao, H. Yang, et S. Tang, " Policies and demonstrations of micro-grids in China: A review ", Renewable and Sustainable Energy Reviews, vol. 29, p. 701-718, Jan. 2014, doi: 10.1016/j.rser.2013.09.015.

[12] G. Foggia, M. Muscholl, J-C. Passelergue, P. Gambier-Morel, C. Vuillecard, J-P. Krivine et al., " The Nice Grid project : Using Distributed Energy Resources to Reduce Power Demand through Advanced Network Management », présented at 2014 CIGRE Session, August 2014. Consulted on: Sept. 07, 2020. [En ligne]. Available at: https://hal-mines-paristech.archives-ouvertes.fr/hal01112769

[13] W. Beitz et K.-H. Küttner, Handbook of Mechanical Engineering. London: Springer-Verlag, 1994. doi: 10.1007/978-1-4471-3566-1.

[14] « Aspen Capital Cost Estimator ». https://www.aspentech.com/en/products/engineering/aspencapital-cost-estimator

[15] « SimaPro ». https://simapro.com/

[16] H. Kanchev, D. Lu, F. Colas, V. Lazarov, et B. Francois, « Energy Management and Operational Planning of a Microgrid With a PV-Based Active Generator for Smart Grid Applications ", IEEE Transactions on Industrial Electronics, vol. 58, $\mathrm{n}^{\circ}$ 10, p. 4583-4592, Oct. 2011, doi: 10.1109/TIE.2011.2119451.

[17] C. Darras, M. Muselli, P. Poggi, C. Voyant, J.-C. Hoguet, et F. Montignac, « PV output power fluctuations smoothing: The MYRTE platform experience ", International Journal of Hydrogen Energy, vol. 37, n 19, p. 14015-14025, Oct. 2012, doi: 10.1016/j.ijhydene.2012.07.083. 
[18] J. Wasilewski, « Optimisation of multicarrier microgrid layout using selected metaheuristics ", International Journal of Electrical Power \& Energy Systems, vol. 99, p. 246-260, Jul. 2018, doi: 10.1016/j.ijepes.2018.01.022.

[19] N. Nikmehr et S. N. Ravadanegh, " Optimal Power Dispatch of Multi-Microgrids at Future Smart Distribution Grids », IEEE Transactions on Smart Grid, vol. 6, n 4, p. 1648-1657, Jul. 2015, doi: 10.1109/TSG.2015.2396992.

[20] A. T. D. Perera, R. A. Attalage, K. K. C. K. Perera, et V. P. C. Dassanayake, « A hybrid tool to combine multi-objective optimization and multi-criterion decision making in designing standalone hybrid energy systems ", Applied Energy, vol. 107, p. 412-425, Jul. 2013, doi: 10.1016/j.apenergy.2013.02.049.

[21] G. Carpinelli, F. Mottola, D. Proto, et A. Russo, « A Multi-Objective Approach for Microgrid Scheduling ", IEEE Transactions on Smart Grid, vol. 8, n 5, p. 2109-2118, Sept. 2017, doi: 10.1109/TSG.2016.2516256.

[22] P. Kayal et C. K. Chanda, « Optimal mix of solar and wind distributed generations considering performance improvement of electrical distribution network », Renewable Energy, vol. 75, p. 173-186, March 2015, doi: 10.1016/j.renene.2014.10.003.

[23] C. Wang, B. Yu, J. Xiao, et L. Guo, « Multi-scenario, multi-objective optimization of grid-parallel Microgrid ", in 2011 4th International Conference on Electric Utility Deregulation and Restructuring and Power Technologies (DRPT), Weihai, China, Jul. 2011, p. 1638-1646. doi: 10.1109/DRPT.2011.5994160.

[24] R. N. S. R. Mukhtaruddin, H. A. Rahman, M. Y. Hassan, et J. J. Jamian, « Optimal hybrid renewable energy design in autonomous system using Iterative-Pareto-Fuzzy technique », International Journal of Electrical Power \& Energy Systems, vol. 64, p. 242-249, Jan. 2015, doi: 10.1016/j.ijepes.2014.07.030.

[25] T. Niknam, R. Azizipanah-Abarghooee, et M. R. Narimani, « An efficient scenario-based stochastic programming framework for multi-objective optimal micro-grid operation », Applied Energy, vol. 99, p. 455-470, Nov. 2012, doi: 10.1016/j.apenergy.2012.04.017.

[26] A. Kamjoo, A. Maheri, A. M. Dizqah, et G. A. Putrus, " Multi-objective design under uncertainties of hybrid renewable energy system using NSGA-II and chance constrained programming ", International Journal of Electrical Power \& Energy Systems, vol. 74, p. 187-194, Jan. 2016, doi: 10.1016/j.ijepes.2015.07.007.

[27] L. Wang et C. Singh, « Multicriteria Design of Hybrid Power Generation Systems Based on a Modified Particle Swarm Optimization Algorithm ", IEEE Transactions on Energy Conversion, vol. 24, n 1, p. 163-172, March 2009, doi: 10.1109/TEC.2008.2005280.

[28] H. R. E.-H. Bouchekara, M. S. Javaid, Y. A. Shaaban, M. S. Shahriar, M. A. M. Ramli, et Y. Latreche, " Decomposition based multiobjective evolutionary algorithm for PV/Wind/Diesel Hybrid Microgrid System design considering load uncertainty ", Energy Reports, vol. 7, p. 52-69, Nov. 2020, doi: 10.1016/j.egyr.2020.11.102.

[29] M. A. M. Ramli, H. R. E. H. Bouchekara, et A. S. Alghamdi, « Optimal sizing of PV/wind/diesel hybrid microgrid system using multi-objective self-adaptive differential evolution algorithm ", Renewable Energy, vol. 121, p. 400-411, June 2018, doi: 10.1016/j.renene.2018.01.058.

[30] E. Ridha, L. Nolting, et A. Praktiknjo, « Complexity profiles: A large-scale review of energy system models in terms of complexity ", Energy Strategy Reviews, vol. 30, p. 100515, Jul. 2020, doi: 10.1016/j.esr.2020.100515.

[31] P. Matarasso, " Présentation de deux modèles emblématiques de l'analyse des politiques économiques du changement climatique : MARKAL et DICE », 2003, Consulted on: August 15, 2019. [Online]. Available on: https://halshs.archives-ouvertes.fr/halshs-00007214

[32] A. Manne, R. Mendelsohn, et R. Richels, " MERGE: A model for evaluating regional and global effects of GHG reduction policies », Energy Policy, vol. 23, n 1, p. 17-34, Jan. 1995, doi: 10.1016/0301-4215(95)90763-W.

[33] A. S. Manne, « Global 2100: An Almost Consistent Model of CO2 Emission Limits », p. 17. 
[34] P. Rafaj et S. Kypreos, « Internalisation of external cost in the power generation sector: Analysis with Global Multi-regional MARKAL model », Energy Policy, vol. 35, n² 2, p. 828-843, Feb. 2007, doi: 10.1016/j.enpol.2006.03.003.

[35] W. D. Nordhaus, "The "DICE" Model: Background and Structure of a Dynamic Integrated Climate-Economy Model of the Economics of Global Warming ", Cowles Foundation for Research in Economics, Yale University, 1009, févr. 1992. Consulted on: August 22, 2019. [Online]. Disponible sur: https://ideas.repec.org/p/cwl/cwldpp/1009.html

[36] Y. Wu, K. Li, N. Li, S. Li, et L. Wang, "Optimization of Controller Parameters for Energy Saving ", IFAC Proceedings Volumes, vol. 47, $n^{\circ} 3$, p. 10281-10286, Jan. 2014, doi: 10.3182/20140824-6ZA-1003.02361.

[37] U. Sureshkumar, P. S. Manoharan, et A. P. S. Ramalakshmi, « Economic cost analysis of hybrid renewable energy system using HOMER ", in IEEE-International Conference On Advances In Engineering, Science And Management (ICAESM -2012), March 2012, p. 94-99.

[38] L. Roucoules et S. Tichkiewitch, « Knowledge synthesis by least commitment for product design ", CIRP Annals, vol. 64, n 1, p. 141-144, Jan. 2015, doi: 10.1016/j.cirp.2015.04.022.

[39] E. Strantzali et K. Aravossis, "Decision making in renewable energy investments: A review ", Renewable and Sustainable Energy Reviews, vol. 55, p. 885-898, March 2016, doi: 10.1016/j.rser.2015.11.021.

[40] D. Fioriti, S. Pintus, G. Lutzemberger, et D. Poli, « Economic multi-objective approach to design off-grid microgrids: A support for business decision making ", Renewable Energy, vol. 159, p. 693-704, Oct. 2020, doi: 10.1016/j.renene.2020.05.154.

[41] S. Sanajaoba et E. Fernandez, " Maiden application of Cuckoo Search algorithm for optimal sizing of a remote hybrid renewable energy System ", Renewable Energy, vol. 96, p. 1-10, Oct. 2016, doi: 10.1016/j.renene.2016.04.069.

[42] T. Khatib, A. Mohamed, K. Sopian, et M. Mahmoud, « Optimal Sizing of Hybrid PV/Wind Systems for Malaysia Using Loss of Load Probability ", Energy Sources, Part A: Recovery, Utilization, and Environmental Effects, vol. 37, nº 7, p. 687-695, April 2015, doi: 10.1080/15567036.2011.592920.

[43] A. N. Celik, " Techno-economic analysis of autonomous PV-wind hybrid energy systems using different sizing methods ", Energy Conversion and Management, vol. 44, $\mathrm{n}^{\circ} 12$, p. 1951-1968, Jul. 2003, doi: 10.1016/S0196-8904(02)00223-6.

[44]T. Tsoutsos, N. Frantzeskaki, et V. Gekas, « Environmental impacts from the solar energy technologies ", Energy Policy, vol. 33, n 3, p. 289-296, Feb. 2005, doi: 10.1016/S03014215(03)00241-6.

[45] L. Stougie, N. Giustozzi, H. van der Kooi, et A. Stoppato, «Environmental, economic and exergetic sustainability assessment of power generation from fossil and renewable energy sources ", International Journal of Energy Research, vol. 42, n 9, p. 2916-2926, 2018, doi: 10.1002/er.4037.

[46] O. Edenhofer, R. Pichs-Madruga, Y. Sokona, J.C. Minx, E. Farahani, S. Kadner et al., Éd., IPCC, 2014: Climate change 2014: mitigation of climate change: Working Group III contribution to the Fifth Assessment Report of the Intergovernmental Panel on Climate Change. , Cambridge, United Kingdom and New York, NY, USA: Cambridge University Press, 2014.

[47] E. Schito, P. Conti, L. Urbanucci, et D. Testi, « Multi-objective optimization of HVAC control in museum environment for artwork preservation, visitors' thermal comfort and energy efficiency ", Building and Environment, vol. 180, p. 107018, August 2020, doi: 10.1016/j.buildenv.2020.107018.

[48] G. Liu, M. Li, B. Zhou, Y. Chen, et S. Liao, « General indicator for techno-economic assessment of renewable energy resources ", Energy Conversion and Management, vol. 156, p. 416-426, Jan. 2018, doi: 10.1016/j.enconman.2017.11.054.

[49] D. Abbes, A. Martinez, et G. Champenois, « Life cycle cost, embodied energy and loss of power supply probability for the optimal design of hybrid power systems ", Mathematics and Computers in Simulation, vol. 98, p. 46-62, April 2014, doi: 10.1016/j.matcom.2013.05.004.

[50] T. Kerdphol, K. Fuji, Y. Mitani, M. Watanabe, et Y. Qudaih, "Optimization of a battery energy storage system using particle swarm optimization for stand-alone microgrids ", International 
Journal of Electrical Power \& Energy Systems, vol. 81, p. 32-39, Oct. 2016, doi: 10.1016/j.ijepes.2016.02.006.

[51] E. Zitzler et L. Thiele, " Multiobjective evolutionary algorithms: a comparative case study and the strength Pareto approach ", IEEE Transactions on Evolutionary Computation, vol. 3, $\mathrm{n}^{\circ} 4$, p. 257-271, Nov. 1999, doi: 10.1109/4235.797969.

[52] E. Zitzler, M. Laumanns, et L. Thiele, « SPEA2 : Improving the Strength Pareto Evolutionary Algorithm », ETH Zurich, 2001, doi: 10.3929/ethz-a-004284029.

[53] K. Deb, S. Agrawal, A. Pratap, et T. Meyarivan, « A Fast Elitist Non-dominated Sorting Genetic Algorithm for Multi-objective Optimization: NSGA-II ", in Parallel Problem Solving from Nature PPSN VI, 2000, p. 849-858.

[54] J. Knowles et D. Corne, « The Pareto Archived Evolution Strategy: A New Baseline Algorithm for Pareto Multiobjective Optimisation », Jan. 1999, vol. 1. doi: 10.1109/CEC.1999.781913.

[55] D. Dumitrescu, M. Oltean, et C. Groşan, « A New Evolutionary Adaptive Representation Paradigm ", 2001.

[56] D. Fioriti, G. Lutzemberger, D. Poli, P. Duenas-Martinez, et A. Micangeli, « Coupling economic multi-objective optimization and multiple design options: A business-oriented approach to size an off-grid hybrid microgrid ", International Journal of Electrical Power \& Energy Systems, vol. 127, p. 106686, May 2021, doi: 10.1016/j.ijepes.2020.106686.

[57] The Wind Power, "Vestas V902/2000 », The Wind Power. https://www.thewindpower.net/turbine_fr_32_vestas_v90-2000.php (consulté le juin 16, 2021).

[58] A. S. O. Ogunjuyigbe, T. R. Ayodele, et O. A. Akinola, "Optimal allocation and sizing of $\mathrm{PV} /$ Wind/Split-diesel/Battery hybrid energy system for minimizing life cycle cost, carbon emission and dump energy of remote residential building ", Applied Energy, vol. 171, p. 153-171, June 2016, doi: 10.1016/j.apenergy.2016.03.051.

[59] B. Multon, J. Aubry, P. Haessig, et H. B. Ahmed, " Systèmes de stockage d'énergie électrique ", p. 33, 2013.

[60] E. Assoumou, « Modélisation MARKAL pour la planification énergétique long terme dans le contexte français ", École Nationale Supérieure des Mines de Paris, 2006. Consulted on: June 17, 2019. [Online]. Available on: https://pastel.archives-ouvertes.fr/pastel-00002752

[61] A. Nottrott, J. Kleissl, et B. Washom, « Energy dispatch schedule optimization and cost benefit analysis for grid-connected, photovoltaic-battery storage systems ", Renewable Energy, vol. 55, p. 230-240, Jul. 2013, doi: 10.1016/j.renene.2012.12.036.

[62] H. R. Baghaee, M. Mirsalim, G. B. Gharehpetian, et H. A. Talebi, « Reliability/cost-based multiobjective Pareto optimal design of stand-alone wind/PV/FC generation microgrid system ", Energy, vol. 115, p. 1022-1041, Nov. 2016, doi: 10.1016/j.energy.2016.09.007.

[63]X. Ouyang et B. Lin, « Levelized cost of electricity (LCOE) of renewable energies and required subsidies in China ", Energy Policy, vol. 70, p. 64-73, Jul. 2014, doi: 10.1016/j.enpol.2014.03.030.

[64] IEA, " Projected Costs of Generating Electricity 2020 », IEA, Paris, 2020. Consulted on: Jul. 01, 2021. [Online]. Available on: https://www.iea.org/reports/projected-costs-of-generatingelectricity-2020

[65] D. Ray, " Lazard's Levelized Cost of Energy Analysis-Version 13.0 », p. 20, 2019.

[66] O. Schmidt, S. Melchior, A. Hawkes, et I. Staffell, « Projecting the Future Levelized Cost of Electricity Storage Technologies », Joule, vol. 3, n 1, p. 81-100, Jan. 2019, doi: 10.1016/j.joule.2018.12.008.

[67] P. Denholm et G. L. Kulcinski, « Life cycle energy requirements and greenhouse gas emissions from large scale energy storage systems ", Energy Conversion and Management, vol. 45, $n^{\circ} 13, \mathrm{p}$. 2153-2172, August 2004, doi: 10.1016/j.enconman.2003.10.014.

[68] L. G. Acuña, R. V. Padilla, et A. S. Mercado, « Measuring reliability of hybrid photovoltaic-wind energy systems: A new indicator ", Renewable Energy, vol. 106, p. 68-77, June 2017, doi: 10.1016/j.renene.2016.12.089. 
[69] R. Luna-Rubio, M. Trejo-Perea, D. Vargas-Vázquez, et G. J. Ríos-Moreno, « Optimal sizing of renewable hybrids energy systems: A review of methodologies ", Solar Energy, vol. 86, $n^{\circ} 4$, p. 1077-1088, April 2012, doi: 10.1016/j.solener.2011.10.016.

[70] N. Dougier, P. Garambois, J. Gomand, et L. Roucoules, « Systemic Approach for Local Energy Mix Assessment ", in Advances on Mechanics, Design Engineering and Manufacturing III, Cham, 2021, p. 143-148. doi: 10.1007/978-3-030-70566-4_23.

[71] K. Deb, A. Pratap, S. Agarwal, et T. Meyarivan, « A fast and elitist multiobjective genetic algorithm: NSGA-II », IEEE Transactions on Evolutionary Computation, vol. 6, n² 2, p. 182-197, April 2002, doi: 10.1109/4235.996017. 